\title{
REVENUE-RAISING VS. OTHER APPROACHES TO ENVIRONMENTAL PROTECTION: THE CRITICAL SIGNIFICANCE OF PRE-EXISTING TAX DISTORTIONS
}

\author{
Lawrence H. Goulder \\ Ian W. H. Parry \\ Dallas Burtraw
}

Working Paper 5641

\author{
NATIONAL BUREAU OF ECONOMIC RESEARCH \\ 1050 Massachusetts Avenue \\ Cambridge, MA 02138 \\ June 1996
}

The authors gratefully acknowledge the helpful comments and suggestions of Gary Becker, Sjak Smulders, David Starrett, George Tolley, and seminar participants at Harvard University, the University of Chicago, the University of California at Berkeley and the University of California at Santa Barbara. We also thank Koshy Mathai, Akila Weerapana and Roberton Williams for outstanding research assistance, and the National Science Foundation (Grant 9310362) and IBM Corporation for financial support. This paper is part of NBER's research program in Public Economics. Any opinions expressed are those of the authors and not those of the National Bureau of Economic Research.

(C) 1996 by Lawrence H. Goulder, Ian W. H. Parry and Dallas Burtraw. All rights reserved. Short sections of text, not to exceed two paragraphs, may be quoted without explicit permission provided that full credit, including $(\mathcal{O}$ notice, is given to the source. 


\author{
REVENUE-RAISING VS. OTHER \\ APPROACHES TO ENVIRONMENTAL \\ PROTECTION: THE CRITICAL \\ SIGNIFICANCE OF PRE-EXISTING \\ TAX DISTORTIONS
}

\begin{abstract}
This paper examines the choice between revenue-raising and non-revenue-raising instruments for environmental protection in a second-best setting with pre-existing factor taxes. We find that interactions with pre-existing taxes fundamentally influence the costs of regulation and seriously militate against pollution abatement policies that do not raise revenue. Indeed, if the marginal environmental benefits from pollution reductions are below a certain threshold value, then any amount of pollution abatement through non-revenue-raising (NRR) policies like emissions quotas is efficiency-reducing. Under conditions roughly approximating $\mathrm{SO}_{2}$ emissions from electric power plants in the U.S., efficiency gains vanish if marginal environmental benefits are below $\$ 109$ per ton and an NRR policy is employed. Moreover, imposing the "Pigouvian" (rather than second-best optimal) level of quotas can reduce welfare, even when environmental benefits are as high as $\$ 220$ per ton. These results are largely independent of the size of the regulated sector relative to the overall economy.

These findings stem from two underlying effects. The tax-interaction effect is the adverse impact in factor markets arising from reductions in after-tax returns to factors associated with the higher production costs caused by environmental regulation. This effect leads to significantly higher efficiency costs than what would apply in a first-best world with no pre-existing taxes. Revenue-raising regulations (taxes) enjoy a revenue-recycling effect that offsets much of the taxinteraction effect, but non-revenue-raising regulations (quotas) enjoy no such offset. Consequently, for any given target level of emissions reduction, the gross efficiency costs of nonrevenue-raising policies are higher than those of revenue-raising policies.

These general equilibrium results are relevant to government regulation outside the environmental area. To the extent that government regulations of international trade or agricultural production raise the costs of output and thereby reduce real factor returns, they can generate much higher social costs than would be indicated by partial equilibrium analyses.
\end{abstract}

Lawrence H. Goulder Department of Economics

Stanford University

Stanford, CA 94305-6072 and NBER
Ian W. H. Parry

Resources for the Future

1616 P Street, NW

Washington, DC 20036
Dallas Burtraw

Resources for the Future

1616 P Street, NW

Washington, DC 20036 


\section{Introduction}

In choosing among alternative instruments for achieving environmental improvement, an important consideration is whether the instrument in question raises revenue. Revenue-raising $(R R)$ instruments include taxes on emissions of pollution (e.g, releases of chlorofluorocarbons), or on inputs, goods or services closely associated with pollution (e.g., gasoline). They also include tradeable emissions permits in cases where the permits are sold or auctioned by the regulatory agency when they are first made available. Non-revenueraising (NRR) instruments include mandated technologies, performance standards, and tradeable permits when emissions permits are initially given out free (or grandfathered). ${ }^{1}$

During the past decade, a number of economists have pointed out an important attraction of RR instruments over NRR instruments. Oates and Schwab (1988), Poterba (1993), Repetto et al. (1992) and others have emphasized that $R R$ instruments enable the public sector to finance cuts in existing, distortionary taxes, thereby avoiding some of the deadweight cost associated with these taxes. The efficiency benefit from using revenues to finance cuts in the marginal rates of existing taxes (relative to when they are returned lump sum) has been termed the revenue-recycling effect (Goulder [1995]). Numerical investigations by Terkla (1984) and Ballard and Medema (1993), along with those reported in Repetto et al. (1992) and Shackleton et al. (1995), indicate that such revenue-recycling can substantially lower the aggregate social cost of environmental regulation relative to the case where no revenues are raised or, equivalently, where revenues are not used to cut marginal tax rates.

Recent explorations in second-best environmental taxation suggest, however, that there may be much more at stake in the choice between RR and NRR instruments than previously thought. Beyond suggesting that NRR policies are at a disadvantage relative to RR policies, this work calls in question the ability of NRR policies to yield efficiency gains. Analytical work by Bovenberg and de Mooij (1994), Bovenberg and van der Ploeg (1994), and Parry (1995) has shown that, by driving up the price of (polluting) goods relative to leisure, environmental taxes tend to compound the distortions caused by taxes in labor markets. In general, the negative welfare impact associated with this tax-interaction effect dominates the positive influence of the

${ }^{1}$ Besides reducing pollution, the choice between $\mathrm{RR}$ and NRR policies applies to a wide range of other public policy objectives, including reducing traffic congestion, drug use, smoking, household garbage generation, depletion of fish stocks and destruction of natural habitats. 
revenue-recycling effect and implies that, overall, environmental regulations are more costly in a second-best setting with pre-existing distortionary taxes than in a first-best situation where no other taxes are present. ${ }^{2}$ Moreover, this research indicates that environmental taxes which fail to exploit the revenue-recycling effect -as in the case where revenues are returned to the economy through lump-sum tax cuts rather than through cuts in marginal tax rates -- may be unable to generate an efficiency improvement ${ }^{3}$ no matter what level of pollution reduction is attempted! In this connection, numerical simulations by Bovenberg and Goulder (1996) indicate that a carbon tax whose revenues are returned lump-sum cannot improve economic efficiency (regardless of the size of the carbon tax) if the marginal environmental benefits from carbon abatement are less than $\$ 50$ per ton.

Like environmental tax policies in which revenues are returned lump sum, NRR policies fail to exploit the revenue-recycling effect. Yet, as discussed below, they produce a (costly) tax-interaction effect similar to that of environmental taxes. This suggests that, in a second-best setting, the serious limitations to efficiency that apply to environmental tax policies in which revenues are returned lump-sum may apply equally to NRR policies. The disadvantage of NRR instruments may be large enough to make efficiency improvements impossible with these instruments no matter what the level of pollution reduction. In other words, the revenue-recycling effect might not only influence the relative impacts of NRR and RR policies but also dictate whether the welfare impact under NRR policies is positive. ${ }^{4}$

This paper examines the choice between RR and NRR instruments in a second-best setting where distortionary taxes are present. We analyze how the magnitude of existing taxes alters both the relative efficiency effects of these two types of instruments and the absolute efficiency effects -- in particular, the prospects for positive efficiency impacts. We begin with a simple model that yields analytical results and

\footnotetext{
${ }^{2}$ This implies that the optimal pollution tax in a second-best setting is usually lower than the "Pigouvian" $\operatorname{tax}$ rate or marginal environmental damage. Bovenberg and Goulder (1996) and Parry (1995) find the optimal tax to be about 30 percent below the Pigouvian rate under plausible values for parameters and pre-existing tax rates. These results are consistent with earlier theoretical contributions in the optimal tax literature. See, for example, Sandmo (1975), $\mathrm{Ng}$ (1980), and the discussion in Auerbach (1985).

${ }^{3}$ By "efficiency improvement" we mean a positive aggregate net benefit from the environmental policy, where the net benefit is the gross social benefit stemming from the reduction in pollution minus the social cost of pollution abatement.

${ }^{4}$ Of course there are other important considerations in instrument choice, including administrative ease, monitoring and enforcement costs, the probability distribution of policy errors in the presence of uncertainty, effects on the distribution of economic rents, and political feasibility. (There is a very large literature on how these other considerations might influence instrument choice. See, for example, Hahn [1986], Nichols [1984], Stavins [1991], and Weitzman [1974]). To the extent that NRR instruments are revealed to be at a serious disadvantage along the efficiency dimensions we discuss, the larger the advantages along these other dimensions must be to justify their adoption.
} 
then extend the model gradually to gain greater realism. As we extend the original model, we give up the opportunity to obtain analytical solutions and must solve through numerical simulation. For concreteness we gauge model parameters and industry definitions to approximate circumstances faced by U.S. policy makers in the drafting of provisions of the 1990 Clean Air Act Amendments applying to sulfur dioxide emissions from coal-fired electric power plants. But the insights apply to other settings, including the abatement of carbon emissions on the national or international level through taxes or tradeable permits.

The paper is organized as follows. Section II lays out the central theoretical issues and obtains initial results using a simple analytical model. This model has a similar focus to the graphical analysis in Parry (1996) -- the only previous paper we know of on this topic -- but differs from that paper in providing an explicit utility-maximizing basis for the welfare results. Section III extends the original model, where the extensions include attention to intermediate inputs and a broader set of options for pollution abatement. The extended model is applied numerically in Section IV. This section explores further how tax interactions affect the net welfare gains from pollution-abatement policies, and examines when these interactions can offset the entire "Pigouvian" welfare gain from pollution abatement. Section V analyzes further the sensitivity of the results to parameters and model specifications. Section VI offers conclusions.

\section{Analytical Foundations and Results}

\section{A. The Basic Model ${ }^{5}$}

A representative agent model is assumed in which household utility is

(II.1) $U(u(X, Y, l), Q)$

where $U($.$) and the subutility function u($.) satisfy the usual properties of continuity and local quasiconcavity. $X$ and $Y$ are market goods, $l$ is leisure or non-market time, and $Q$ is the quality of the environment. Weak separability between environmental and non-environmental goods implies that the demand functions for $X, Y$ and $l$ are independent of $Q{ }^{6}$

${ }^{5}$ This section adopts an approach similar to that taken in recent unpublished notes by David Starrett.

${ }^{6}$ This is a common simplifying assumption. Using a more general utility function would not affect the key result in this section. which compares pollution taxes and quotas at a given level of environmental quality. 
$X$ and $Y$ are produced by competitive firms using labor as the only input. The marginal product of labor in both industries is constant, and unaffected by environmental quality. Normalizing units to imply transformation rates of unity, we can write the economy's resource constraint as:

$$
T=X+Y+l
$$

where $T$ is the household time endowment ( $T-l$ is labor supply).

The production of $X$ causes waste emissions that harm the environment; that is:

$$
\text { (II.3) } Q=Q(X)
$$

where $Q_{X}<0{ }^{7}$ From (II. 1) and (II.3), we can define marginal environmental damages from production of $X$ in dollars by

$$
D(X)=-\frac{1}{\lambda} U_{Q} Q_{X}
$$

where $\lambda$ is the marginal utility of income. We make the usual assumption that $D^{\prime}(X) \geq 0$. In the absence of policy intervention, there is assumed to be no internalization of environmental damages by firms or households

Finally, the government has an exogenous total revenue requirement $T R$, levies a proportional tax of $\tau_{L}$ on labor income, and regulates $X$. For our purposes it does not matter what $T R$ is used for; we assume it is returned to households as a lump sum transfer. ${ }^{8}$

\section{B. Pollution Taxes (Revenue-Raising Instruments)}

Suppose a tax of $\tau_{X}$ per unit is imposed on $X$. Normalizing the gross wage to unity, we can express the household budget constraint as

$$
\left(1+\tau_{X}\right) X+Y=\left(1-\tau_{L}\right)(T-l)+T R
$$

As usual, households are assumed to maximize utility (II. 1) subject to their budget constraint (II.5), taking environmental quality as given. This yields the first order conditions

$$
U_{X}=\left(1+\tau_{X}\right) \lambda ; \quad U_{Y}=\lambda ; \quad U_{l}=\left(1-\tau_{L}\right) \lambda
$$

From (II.5) and (II.6) we can implicitly derive the (uncompensated) demand functions

${ }^{7}$ Therefore, reducing waste emissions requires reducing output. More generally, this can also be achieved by substituting waste emissions for other inputs in production. However, as we demonstrate below in the numerical model, substitution in production does not substantially reduce the relative size of interactions with the tax system.

${ }^{8}$ An alternative specification would incorporate $T R$ as a public good in the household utility function. This produces the same results as in our model, since $T R$ is held constant. 
$X\left(\tau_{X}, \tau_{L}\right) ; \quad Y\left(\tau_{X}, \tau_{L}\right) ; l\left(\tau_{X}, \tau_{L}\right)$

Government revenues are the sum of labor and pollution tax revenues. Therefore government budget balance requires

$$
T R=\tau_{L}(T-l)+\tau_{X} X
$$

We now consider a revenue-neutral policy involving an increase in $\tau_{X}$ and reduction in $\tau_{L}$. Substituting (II.7) in (II .8) and totally differentiating while holding $T R$ constant gives

$$
\frac{d \tau_{L}}{d \tau_{X}}=-\frac{X+\tau_{X} \frac{\partial X}{\partial \tau_{X}}-\tau_{L} \frac{\partial l}{\partial \tau_{X}}}{T-l-\tau_{L} \frac{\partial l}{\partial \tau_{L}}+\tau_{X} \frac{\partial X}{\partial \tau_{L}}}
$$

This equation is the reduction in labor tax that can be financed by a marginal increase in the environmental tax, while maintaining budget balance. Differentiating the resource constraint (II.2) yields the following condition for the aggregate quantity effects of the policy change:

$$
\frac{\partial X}{\partial \tau_{X}}+\frac{\partial Y}{\partial \tau_{X}}+\frac{\partial l}{\partial \tau_{X}}+\left\{\frac{\partial X}{\partial \tau_{L}}+\frac{\partial Y}{\partial \tau_{L}}+\frac{\partial l}{\partial \tau_{L}}\right\} \frac{d \tau_{L}}{d \tau_{X}}=0
$$

Using (II. 1), (II.3) and (II.7) the welfare effect from a marginal change in $\tau_{X}$, allowing for changes in household demands and in the value of $\tau_{L}$, is

$$
\frac{d U}{d \tau_{X}}=U_{X} \frac{\partial X}{\partial \tau_{X}}+U_{Y} \frac{\partial Y}{\partial \tau_{X}}+U_{l} \frac{\partial l}{\partial \tau_{X}}+U_{Q} Q_{X} \frac{\partial X}{\partial \tau_{X}}+\left\{U_{X} \frac{\partial X}{\partial \tau_{L}}+U_{Y} \frac{\partial Y}{\partial \tau_{L}}+U_{l} \frac{\partial l}{\partial \tau_{L}}+U_{Q} Q_{X} \frac{\partial X}{\partial \tau_{L}}\right\} \frac{d \tau_{L}}{d \tau_{X}}
$$

Substituting the expressions for marginal environmental damages (II.4), marginal utility from consumption (II.6), and the aggregation property (II.10), gives

$$
\frac{1}{\lambda} \frac{d U}{d \tau_{X}}=-\left(D-\tau_{X}\right) \frac{\partial X}{\partial \tau_{X}}-\tau_{L} \frac{\partial l}{\partial \tau_{X}}-\left[\left(D-\tau_{X}\right) \frac{\partial X}{\partial \tau_{L}}+\tau_{L} \frac{\partial l}{\partial \tau_{L}}\right] \frac{d \tau_{L}}{d \tau_{X}}
$$

Substituting from (II.9) and collecting terms gives

$$
\frac{1}{\lambda} \frac{d U}{d \tau_{X}}=-\left(D-\tau_{X}\right) \frac{\partial X}{\partial \tau_{X}}+\frac{\left\{\tau_{L} \frac{d}{\partial \tau_{L}}+\left(D-\tau_{X}\right) \frac{\partial X}{\partial \tau_{L}}\right\}\left\{X+\tau_{X} \frac{\partial X}{\partial \tau_{X}}\right\}-\left\{T-l+D \frac{\partial X}{\partial \tau_{L}}\right\} \tau_{L} \frac{\partial}{\partial \tau_{X}}}{T-l-\tau_{L} \frac{\partial}{\partial \tau_{L}}+\tau_{X} \frac{\partial X}{\partial \tau_{L}}}
$$

Finally, this can be expressed as 
(II.1 I) $\frac{1}{\lambda} \frac{d U}{d \tau_{X}}=\underbrace{\left(D-\tau_{X}\right)\left(-\frac{\partial X}{\partial \tau_{X}}\right)}_{\partial W^{P}}+\underbrace{M\left(X+\tau_{X} \frac{\partial X}{\partial \tau_{X}}\right)}_{\partial W^{R}} \underbrace{-(1+M) \tau_{L} \frac{\partial l}{\partial \tau_{X}}}_{\partial W^{I}}$

where

$$
M=\frac{\tau_{L} \frac{\partial l}{\partial \tau_{L}}-\left(D-\tau_{X}\right)\left(-\frac{\partial X}{\partial \tau_{L}}\right)}{T-l-\tau_{L} \frac{\partial l}{\partial \tau_{L}}+\tau_{X} \frac{\partial X}{\partial \tau_{L}}}
$$

The numerator in (II. 12) is the welfare loss from a marginal increase in the labor tax. This consists of: (i) the increase in leisure multiplied by $\tau_{L}$, the wedge between the gross and net wage; less (ii) the reduction in $X$ multiplied by the gap between marginal social cost $(1+D)$ and the demand price $\left(1+\tau_{X}\right)$ in the $X$ market (assuming $X$ and leisure are substitutes). The denominator is the overall increase in government revenues from a marginal increase in the labor tax (from differentiating (II.8) with respect to $\tau_{L}$ ). Therefore, $M$ is the efficiency cost of raising an additional dollar of revenue by increasing the labor tax, or marginal welfare cost of labor taxation.

Equation (II. I l) decomposes the welfare impact of the policy change into three components. The first is the Pigouvian (or partial equilibrium) effect $\partial W^{P}$. This is the reduction in $X$ from a marginal increase in the environmental tax, multiplied by the wedge between marginal social cost and the demand price, or marginal social benefit. The second is the gain from the (marginal) revenue-recycling effect, $\partial W^{R}$. This is the product of the efficiency value per dollar of tax revenue (the marginal welfare cost of taxation) and the incremental pollution tax revenue. The third is the (marginal) tax-interaction effect, $\partial W^{\perp}$. When $X$ and leisure are substitutes, an increase in the demand price of $X$ increases leisure, which exacerbates the welfare cost of the labor tax by $\tau_{L} \frac{\partial l}{\partial \tau_{X}}$. This also reduces labor tax revenues by $\tau_{L} \frac{\partial l}{\partial \tau_{X}}$. The tax-interaction effect is the welfare loss from these two impacts.

We now compare the revenue-recycling and tax-interaction effects. $\partial W^{I}$ can be manipulated to give the following approximation (see Appendix A)

$$
\partial W^{1}=\phi_{X} M X ; \quad \phi_{X}=\frac{\eta_{X l}^{c}+\eta_{I}}{\frac{X}{X+Y} \eta_{X l}^{c}+\frac{Y}{X+Y} \eta_{Y l}^{c}+\eta_{L I}}
$$


where $\eta_{x I}^{c}$ and $\eta_{Y I}^{c}$ are the compensated elasticity of demand for $X$ and $Y$ with respect to the price of leisure. and $\eta_{L}$ is the income elasticity of labor supply. $\phi_{X}$ is a measure of the degree of substitution between $X$ and leisure relative to that between aggregate consumption and leisure. $\phi_{X}$ equals unity when $X$ and $Y$ are equal substitutes for leisure ( $\eta_{x}^{c}$ equals $\eta_{Y I}^{c}$ ) and is greater (less) than unity when $X$ is a relatively strong (weak) substitute for leisure (that is, $\eta_{x a}^{c}$ is greater (less) than $\eta_{Y l}^{\mathrm{c}}$ ). Comparing (II.13) with $\partial W^{R}$ in (II. 11), we see that the (marginal) revenue-recycling effect equals the tax-interaction effect when $\tau_{X}=0$, but dominates it for $\tau_{X}>0$, if $X$ and $Y$ are equal substitutes for leisure. Therefore, the net effect from interactions with the tax system is generally negative. unless $X$ is a sufficiently weak substitute for leisure ( $\phi_{X}$ is sufficiently below unity) ${ }^{9}$

\section{Pollution Quotas (Non-Revenue-Raising Instruments)}

Now consider, in contrast with the pollution tax case, the situation where a binding, non-auctioned quota is imposed so that

(II. 14) $X=\bar{X}$

We denote the post-regulation demand price of $X$ by $p(\bar{X})$. The quota creates rents of $\pi=(p(\bar{X})-I) \bar{X}$, which are returned to households (who own firms). The numerical model incorporates the taxation of these profits. but for the moment we simplify by ignoring this possibility. Therefore $\pi$ appears as an exogenous lump sum component of income in the household budget constraint. The household demand functions can now be summarized by

(II. $\left.7^{\prime}\right) \quad \bar{X} ; \quad Y\left(\bar{X}, \tau_{L}\right) ; l\left(\bar{X}, \tau_{L}\right)$

and since the constraint on $X$ is binding,

(II. 15) $\frac{\partial X}{\partial \tau_{L}}=0$

The key difference compared with the previous case is that the quota policy generates no revenue. Therefore the government budget constraint is

(II.8') $\quad T R=\tau_{L}(T-l)$

${ }^{9}$ The predominance of the tax-interaction effect has recently been discussed by Parry (1995). The result has long been implicit in optimal tax models (for example Sandmo (1975)), which do not decompose the revenuerecycling and tax-interaction effects. 
Differentiating (II. 8'), and using (II. $\left.7^{\prime}\right)$, gives

(II.9') $\frac{d \tau_{L}}{d \bar{X}}=\frac{\tau_{L} \frac{\partial l}{\partial \bar{X}}}{T-l-\tau_{L} \frac{\partial l}{\partial \tau_{L}}}$

Also, differentiating (II.2) and using (II.15) gives the following aggregation property

(II. $\left.10^{\prime}\right) 1+\frac{\partial Y}{\partial \bar{X}}+\frac{\partial l}{\partial \bar{X}}+\left\{\frac{\partial Y}{\partial \tau_{L}}+\frac{\partial l}{\partial \tau_{L}}\right\} \frac{d \tau_{L}}{d \bar{X}}=0$

Differentiating utility with respect to $\bar{X}$ and $\tau_{L}$, and performing the analogous substitutions to before gives

(II. I 1') $\frac{1}{\lambda} \frac{d U}{d \bar{X}}=\{(p(\bar{X})-1)-D\}-\left(1+M^{\prime}\right) \tau_{L} \frac{\partial l}{\partial \bar{X}}$

where

(II.12') $M^{\prime}=\frac{\tau_{L} \frac{\partial l}{\partial \tau_{L}}}{T-l-\tau_{L} \frac{\partial l}{\partial \tau_{L}}}$

$M^{\prime}$, the marginal welfare cost of labor taxation, is more simple than before, since (from (II. 15)), there is no effect in the $X$ market from increasing $\tau_{L}$. Multiplying (II.11') through by $\frac{\partial \bar{X}}{\partial \tau_{X}}$ and substituting $p(\bar{X})=1+\tau_{X}$ gives

(II. I 1") $\frac{1}{\lambda} \frac{d U}{d \bar{X}} \frac{\partial \bar{X}}{\partial \tau_{X}}=\underbrace{-\left(D-\tau_{X}\right) \frac{\partial \bar{X}}{\partial \tau_{X}}}_{\partial W^{P}}-\underbrace{-\left(1+M^{\prime}\right) \tau_{L} \frac{\partial l}{\partial \bar{X}} \frac{\partial \bar{X}}{\partial \tau_{X}}}_{\partial W^{I}}$

which shows the effect of a quota that has the same effect on the output of $X$ as a change in $\tau_{x}$ Comparing (II. 1 1") with (II.11), the Pigouvian and tax-interaction effects from regulation are analogous to before. However, in the quota case there is no revenue-recycling effect. Therefore so long as marginal pollution tax revenue is positive, the marginal welfare effect of the tax exceeds that for the quota. Increasing the abatement level reduces the pollution tax base $(X)$ and increases the revenue loss $\left(-\tau_{X}\left(\partial X / \partial \tau_{X}\right)\right)$ from incremental reductions in $X$; that is the marginal revenue-recycling effect is 
declining. This implies that the discrepancy between the marginal costs of the tax and quota becomes smaller with the extent of abatement, so long as $M$ is not falling with the amount of abatement.

\section{Welfare Implications of Instrument Choice}

The traditional Pigouvian analysis implies that environmental regulation can increase welfare so long as marginal environmental damages are positive. This is true for the pollution tax in the above model, when $X$ and $Y$ are equal substitutes for leisure $\left(\phi_{X}=1\right)$. However in the pollution quota case, where there is no revenue-recycling effect the incremental welfare change from regulation is positive at $\tau_{X}=0$ when $\partial W^{P}>\partial W^{I}$, or using (II.11") and (II.13)

(II.16) $\widetilde{D}>\frac{\phi_{x} M^{\prime}}{\eta_{x x}}$

where $\eta_{x x}=-\frac{\partial X}{\partial \tau_{X}} \frac{1}{X}$ is the (magnitude of the) own price elasticity of demand for $X$ and $\bar{D}$ is marginal environmental damages expressed relative to marginal production costs.

Some quick calculations show that this can be crucial to welfare impacts. The marginal welfare cost of labor taxation generated by the numerical model is (approximately) 0.3 (see below). Using this value, if the elasticity of demand for the polluting good is $0.5,1$ or 2, then marginal environmental damages must exceed $60 \%, 30 \%$ or $15 \%$ respectively of marginal production costs, or else any level of quola necessarily reduces welfare (when $X$ and $Y$ are equal substitutes for leisure). ${ }^{10}$

Hence this simple analytical model indicates that the magnitude and even the sign of the welfare effects can hinge critically on whether a revenue-raising or non-revenue-raising instrument is used. Below, we examine these issues further using a numerical model that enables us to avoid some of the simplifying assumptions of the present model.

\section{A Numerical Model}

The analytical results above indicate the NRR instruments can face a significant disadvantage relative to RR instruments, especially when marginal environmental benefits of pollution reduction are "low"

\footnotetext{
${ }^{10}$ When demand curves are linear, this condition implies that a quota can increase welfare if environmental benefits are large enough to imply a Pigouvian (first best) output reduction in excess of 30 percent (Parry [1996]).
} 
relative to production cost. To explore this issue further, we now extend the model to incorporate intermediate inputs (in addition to consumer goods) and to recognize firms' abilities to reduce emissions through abatement expenditure (which reduces the intensity of emissions per unit of output). The extended model does not afford analytical results; hence we obtain solutions numerically. However, the model enables us to consider impacts of large (as opposed to incremental) policy changes, and facilitates sensitivity analysis. In special cases the numerical model reduces to the same structure as the analytical model; this makes it possible to identify (in Section V) the significance of the new features in the numerical model.

The extended model has the following elements. There are two intermediate goods, electricity $(E)$ and a "general intermediate good" $(G)$. In addition, there are two consumer goods: an electricity-intensive good $\left(C_{I}\right)$ and a non-electricity-intensive good $\left(C_{N}\right)$. There is one primary factor of production, labor time, which is allocated to production of $E, G, C_{I}$, and $C_{N}$ and to leisure ( $\ell$ ). Labor applied to production again faces the marginal tax rate, $\tau_{L}$. Electricity production entails emissions of sulfur dioxide $\left(\mathrm{SO}_{2}\right)$. Government policy options include taxes and fixed quantity restrictions on emissions of $\mathrm{SO}_{2}$. Government tax revenues finance transfers to households: as in the original model, there is no consumptive government expenditure.

The types of inputs in the model, and the uses to which they are put, are indicated in Figure 1. In the figure and in the text below, $x_{i j}$ denotes the use of good $i$ by industry $j$. Thus, electricity and the general intermediate good are used as an input into the production of electricity, the general intermediate good, and the two consumer goods. Labor time is allocated to production of the four goods and to leisure. In the figure, emissions of $\mathrm{SO}_{2}$ are represented as an "input" to the production of electricity. This indicates that these emissions can be substituted for other inputs to electricity production: that is, if emissions of $\mathrm{SO}_{2}$ are reduced, the use of ordinary inputs by the electricity sector $\left(x_{L E}, x_{G E}, x_{E E}\right)$ must increase to maintain the same electricity output.

The full set of equations of the model is provided in Appendix B. Here we present the behavioral specifications governing producer and household behavior, along with the equilibrium conditions.

\section{A. Production Technologies}

We assume competitive, price-taking firms and a constant-elasticity-of-substitution (CES) production technology in all industries. Production follows:

(III.1) $X_{i}=\left(\alpha_{L i} L_{i}^{\rho_{i}}+\alpha_{E i} E_{i}^{\rho_{i}}+\alpha_{G i} G_{i}^{\rho_{i}}\right)^{\frac{1}{\rho_{i}}}, \quad i=G, E, C_{I}, C_{N}$ 
where $\rho_{i}$ and the $\alpha_{j i}$ 's are parameters. $\rho$ is related to $\sigma$, the elasticity of substitution: $\rho=(\sigma-l) / \sigma^{11}$

Producers make input decisions in accordance with profit-maximization. For producers in industries other than electricity, profit is the value of output minus expenditure on labor, energy, and materials (see appendix $\mathrm{B}$ ). In the electricity industry, the expression for profit is slightly more complex to account for pollution charges and abatement expenditure. In this industry profit $(\pi)$ is given by:

$$
\pi_{j}=p_{E} X_{j}-p_{L} L_{j}-p_{E} E_{j}-p_{G} G_{j}-p_{Z} Z_{j}-\tau_{S} S_{j}
$$

where $p_{L}, p_{E}$, and $p_{G}$ represent the prices of inputs of labor, electricity, and the general intermediate input, respectively. $Z$ and $S$ represent abatement services and sulfur dioxide emissions, respectively; $p_{Z}$ is the unit price of abatement services (assumed to be equal to the price of labor) and $\tau_{S}$ is the tax rate applied to $\mathrm{SO}_{2}$ emissions. In contrast with the original model of Section II, where the emissions-output ratio was fixed, in this model firms can reduce the ratio of $\mathrm{SO}_{2}$ emissions to output by purchasing abatement equipment or services. The relationship between electricity output, pollution emissions, and abatement services is:

$$
S_{j} / X_{j}=\alpha_{S}-\alpha_{Z}\left(Z_{j} / X_{j}\right)^{\beta}
$$

where $\alpha_{s}, \alpha_{z}$, and $\beta$ are parameters. This formulation asserts that, in the absence of expenditure on abatement services or equipment (that is, when $Z$ is zero), the ratio of $\mathrm{SO}_{2}$ emissions to electricity output is $\alpha_{\mathrm{S} .}{ }^{12}$ To the extent that the firm devotes resources to abatement, this ratio falls. Our data on abatement costs for U.S. electricity producers (see below) indicates that $\beta$ is less than unity: there are increasing marginal costs to $\mathrm{SO}_{2}$ reduction. ${ }^{13}$

\footnotetext{
${ }^{11}$ We abstract from the heterogeneity among firms in given industries and, in particular, the considerable heterogeneity among electric power producers. Considerations of heterogeneity can importantly influence the choice among policy instruments -- for example, the choice between a program of fixed emissions quotas versus a program of tradeable emissions permits. However, these considerations can be separated from the issue, emphasized here, of the significance of whether a given policy raises revenue. For example, the relative efficiency impacts of a system of auctioned tradeable permits (which raises revenue) and a system of grandfathered permits (which does not raise revenue) are largely independent of the extent of heterogeneity across polluters.

${ }^{12}$ With greater industry disaggregation, one could link emissions to the use of specific fuels by the electricity industry. In Section $V$ we apply an extended model which distinguishes coal and other fuel inputs to electricity, and connects sulfur dioxide emissions to the use of the coal input.

${ }^{13}$ We considered modeling abatement costs by including $S$ directly in the CES production function for electricity. However, this has the unfortunate property that if the "price" of the use of $S$ is zero (as is the case in the absence of regulation), firms will use infinite quantities of $S$ (that is, sulfur dioxide emissions will be infinite).
} 
We consider two types of pollution regulation: a tax $\tau_{s}$ on sulfur dioxide emissions and fixed quotas on such emissions. In the tax case, furms choose the level of abatement such that, at the margin, the costs of abatement are equal to the avoided charges on pollution (see Appendix B). In the quota case, each firm $j$ maximizes profits subject to the constraint that $S_{j}=S_{j}{ }^{14}$ As shown in Appendix B, in this case the firm's behavior -- and in particular the quantity of abatement equipment purchased $(Z)$-- is identical to that which the firm would choose if pollution level $S$ had been enforced through a pollution tax. This means we can model the pollution quota case as a tax on emissions, with the "revenues" (quota rents) returned in lumpsum fashion to owners of electricity firms (households). The crucial difference between the case of an actual emissions tax and that of an emissions quota (or virtual emission tax) is that significant ${ }^{15}$ govemment revenues are earned only in the former case; thus the revenue-recycling effect is enjoyed only in that case.

\section{B. Household Behavior}

In its treatment of household behavior, the extended model differs from the earlier model in distinguishing the goods that directly confer utility (the consumption goods) from other (intermediate) goods. The electricity-intensive consumption good corresponds to direct household use of electricity, with the other consumption good representing all other goods and services consumption. As before, household behavior reflects utility-maximizing decisions of a representative household that allocates labor time between work and leisure and allocates income between consumption of the two consumer goods. Income is net of tax wage income plus -- in the case of an emissions quota policy -- net of tax rents. The utility function is:

$$
\begin{aligned}
U & =U\left(\ell, C_{I}, C_{N} S\right) \\
& =\left(\alpha_{l} \ell^{\rho_{u}}+\alpha_{\bar{C}} \bar{C}^{\rho_{u}}\right)^{\frac{1}{\rho_{u}}}+V(S)
\end{aligned}
$$

where

(III.5) $\bar{C}=\left(\alpha_{C I} C_{I}^{\rho_{\bar{c}}}+\alpha_{C N} C_{N}^{\rho_{\bar{c}}}\right)^{\frac{1}{\rho \bar{c}}}$

\footnotetext{
${ }^{14}$ In keeping with the assumption of homogeneous producers, we assume that the aggregate emissions reduction is achieved by equal reductions by all producers.

${ }^{15}$ In fact the quota policy has a slight revenue impact, as discussed in Section IV
} 
The parameter $\rho_{U}$ is related to $\sigma_{U}$, the elasticity of substitution between leisure and overall consumption, $\mathrm{C}$ : $\rho_{U}=\left(\sigma_{U}-1\right) / \sigma_{U}$. C is a CES composite of the two consumption goods, with the substitution between them controlled by $\rho_{\bar{C}}$. Utility depends on $\mathrm{SO}_{2}$ emissions $(S)$ as well as ordinary goods and leisure. The household regards $S$ as exogenous. The impact of $S$ on utility is represented by the function $V$, which here is separable from the effects of goods and leisure

\section{The Government's Budget Constraint}

As in the analytical model, all policies we consider are revenue-neutral: the government must obtain enough revenue to maintain fixed real transfers to households. To the extent that any policy change (e.g., the introduction of a tax on sulfur dioxide emissions) would cause revenues to depart from this required revenue level, such revenue impacts are offset through adjustments to the marginal tax rate on labor income. The government's budget constraint is:

$$
T R=\tau_{L}(T-\ell)+\tau_{R} R E N T+\tau_{S} S
$$

RENT denotes the total rent generated by government policy; these are positive in the case of emissions quotas. For simplicity we usually assume that $\tau_{R}$, the tax rate on rents, has the same value as $\tau_{L}$, the tax rate applying to labor income. (Section V considers an alternative assumption). It should be noted that in the case of the pollution quota, $\tau_{s}$ is zero in (III.6). Although we employ a virtual tax to simulate the quota policy, the revenues earned by this "tax" go directly to households as quota rents. ${ }^{16}$ The quota policy affects the government's budget only indirectly: by producing taxable quota rents and by affecting the real wage and labor supply (which alters labor tax revenues).

\section{Equilibrium Conditions}

The production and household specifications above give rise to a set of supply and demand functions of producers and the household (see Appendix B). The requirements of a general equilibrium are that the demands and supplies of all goods be equal, and that government revenues be equal to the required level of government transfers to households. In addition, each policy involves meeting a given emissions target through either an emissions tax (explicit emissions tax) or an emissions quota (virtual emissions tax). The

\footnotetext{
${ }^{16}$ This virtual tax is analogous to the use of "adders" in electric utility resource planning, which serve as shadow prices affecting decisions. See Burtraw et al. (1995)
} 
requirement that $\mathrm{SO}_{2}$ emissions match this target constitutes another equilibrium condition (see Appendix B). Exploiting the constant-returns-to-scale nature of production, we reduce the number of equilibrium conditions to: (1) aggregate labor demand equals aggregate supply, (2) government revenue equals transfers to households, and (3) aggregate emissions equal $\bar{S}$. Solving the model involves finding the vector of "primary" prices satisfying these conditions. These prices uniquely determine all other prices and thus determine all demands and supplies. The primary prices are $p_{L}$ (the price of labor), $\Delta \tau_{L}$ (the adjustment to the labor tax rate necessary to match revenues with the required level of household transfers) and $\tau_{s}$, the tax rate on emissions. ${ }^{17}$

\section{E. Data}

The benchmark data set for the model is intended to represent roughly the situation in the U.S. in the year 2000. We develop this data set by scaling observed 1990 data on input uses, output levels, and consumption patterns to the year 2000 , assuming a real growth rate of 2.6 percent for all flows. ${ }^{18}$ Elasticities of substitution in the production functions and utility function are taken from the disaggregated general equilibrium data set developed by $\mathrm{Cruz}$ and Goulder (1992). The remaining parameters of the model -- the $\alpha$ distribution parameters -- are calibrated by using the identifying restriction that, under benchmark policy conditions, the model replicate the projected benchmark data. ${ }^{19}$ Table 1 displays benchmark data flows, data sources, and parameter values.

The baseline situation against which policy outcomes are compared assumes no abatement of $\mathrm{SO}_{2}$; in other words, there is no (explicit or virtual) tax on $\mathrm{SO}_{2}$ emissions in the baseline. The baseline equilibrium obviously differs from actual circumstances, but using this baseline permits the clearest assessments of impacts of alternative regulations. Developing baseline values of $\mathrm{SO}_{2}$ emissions is a bit tricky because regulatory constraints on such emissions were introduced under the 1990 Clean Air Act amendments and in fact have been in place for some "new sources" of electric power since 1971. Following NAPAP (1991), we assume that aggregate $\mathrm{SO}_{2}$ emissions in the year 2000 would be 20 million tons in the absence of regulation,

\footnotetext{
${ }^{17} \mathrm{By}$ Walras's Law, one of the excess demand conditions is redundant. To obtain the general equilibrium solution, we fix one of the primary prices (the nominal price of labor is set to one) and solve for values of the remaining primary prices that satisfy conditions (2) and (3). As a check on the model's program, we verify that the redundant excess demand condition is satisfied as well.

${ }^{18}$ This is the average real growth for the U.S. over the period 1985-1994, as reported in Table 699 of the 1985 Statistical Abstract of the U.S.
}

${ }^{19}$ For a discussion of calibration methods for general equilibrium models, see Shoven and Whalley (1992). 
that is, in the baseline scenario. ${ }^{20}$ In actuality, the 1990 Clean Air Act Amendments will limit emissions in the year 2000 to 10 million tons.

We consider a range of values for the abatement cost parameter, $\alpha_{z}$. For a central value, we calibrate this parameter so that electricity producers' marginal costs of $\mathrm{SO}_{2}$ abatement are $\$ 300$ per ton in 1990 dollars when aggregate abatement is 10 million tons (from an unconstrained level of emissions of 20 million tons). ${ }^{21}$

An important parameter is $\sigma_{U}$, the elasticity of substitution between leisure and composite consumption in the utility function. Different values of this parameter imply different values for the elasticity of labor supply and for the marginal welfare cost of taxation. As indicated in Section II, the size of the taxinteraction effect is directly related to these values. We employ several values for $\sigma_{U}$; our central value is 0.79 , selected because it implies an uncompensated labor supply elasticity of 0.15 and a marginal welfare cost of taxation of 0.31 in the baseline or status quo ante situation. ${ }^{22}$

\section{Results from the Numerical Model: Emissions Taxes vs. Quotas}

Here we contrast the costs of a (revenue-raising) emissions tax with a (non-revenue-raising) emissions quota. For these first experiments we calculate a series of equilibria corresponding to policies achieving $\mathrm{SO}_{2}$ reductions ranging from 0.1 million tons to 10 million tons, at increments of 0.1 million tons. In simulating the emissions tax policy, we solve for the value of $\tau_{s}$ that achieves the desired amount of $\mathrm{SO}_{2}$ abatement (or, equivalently, the desired level of emissions, $\bar{S}$ ). Revenues from the emissions tax finance proportional cuts in the marginal tax rate $\tau_{L}$. As discussed in Section III, the quota policy is modeled by way of a virtual tax $\tau_{S}$ that has no direct impact on government revenue but instead yields quota rents that ultimately accrue to households (owners of electricity firms). The emissions tax exploits the revenuerecycling effect because it finances cuts in the marginal tax rate, $\tau_{L}$; in contrast, the quota policy has an

\footnotetext{
${ }^{20}$ The NAPAP "baseline" estimate assumes no enactment of the 1990 Clean Air Act amendments and no subsequent regulation, but allows for (minor) emissions impacts from prior regulations.

${ }^{21}$ This is within the range of estimates from various studies. RDI(1995), USEPA(1995a), and EPRI(1995) respectively estimate marginal abatement costs to be $\$ 195, \$ 462$, and $\$ 339-493$ (1990 dollars) by the year 2010 , when the full, 10 million ton abatement requirement is in force. Emissions allowance prices today are lower than these values, in part because these future costs are discounted to the present.
}

${ }^{22}$ These are central values from the literature. See in particular Ballard et al. (1985) and Browning (1987). 
insignificant gross revenue impact. ${ }^{23}$

\section{A. Relative Costs of RR and NRR Policies: Crucial Determinants}

\section{Relative Costs and Pre-Existing Tax Rates}

Figures $2 \mathrm{a}$ and $2 \mathrm{~b}$ contrast the effects of these policies. In each figure, the horizontal axis is the reduction in aggregate $\mathrm{SO}_{2}$ emissions, in millions of tons. The vertical axis is the marginal welfare cost of obtaining these emissions reductions, expressed in 1990 dollars per ton ${ }^{24}$ Each figure shows the relationship between marginal welfare cost and $\mathrm{SO}_{2}$ reduction under four different assumed values -- 0.0, 0.2, 0.4 (our preferred estimate ${ }^{25}$ ), and 0.6 -- for the pre-existing marginal tax rate, $\tau_{\mathrm{L}}$. It should be noted that the marginal welfare cost reflects changes in the non-environment-related component of the utility function (the first term in equation [III.4]): we do not yet consider welfare effects associated with changes in environmental quality, which fall on the benefit side of the ledger.

Several key findings emerge from these figures. First, for any given type of policy (RR or NRR), the economy's marginal costs are an increasing function of the extent of abatement. This reflects rising marginal costs of abatement at the firm level (equation [III.3]). Second, for either type of policy, marginal costs are increasing functions of $\tau_{L 0}$, the value of the initial labor tax rate. This was predicted by the analytical model. The larger the pre-existing tax rate, the larger the marginal tax-interaction effect for any given amount of

${ }^{23}$ By creating taxable quota rents, it brings in revenue; by eroding the labor tax base, it loses revenue. The net effect is quite small. For example, a quota that reduces aggregate $\mathrm{SO}_{2}$ emissions by 5 million tons has a gross revenue impact (before offsetting adjustments in $\tau_{L}$ ) of $-\$ 69.5$ million, which divides into a revenue gain of $\$ 886.3$ million in taxes from quota rents and a reduction of $\$ 955.8$ million in labor tax revenues. In contrast, a pollution tax that achieves the same abatement has a gross revenue impact of $\$ 1260.0$ million, which divides into $\$ 2215.8$ million in pollution tax revenue and a reduction of $\$ 955.8$ million in labor tax revenue.

${ }^{24}$ We calculate the marginal welfare cost using the equivalent variation measure. Let $E V[s(A), s(B)]$ denote the equivalent variation associated with a change from state $s(A)$ to state $s(B)$, where each state is defined by the set of prices and policy parameters (taxes) faced by the household. The $E V$ is the exogenous increment to the household's income in state $s(A)$ that would enable the household to achieve the same level of utility as it enjoys in state $s(B)$. A positive $E V$ represents a welfare improvement; thus, welfare cost is the negative of the $E V$. The marginal welfare cost associated with the level sulfur reduction $R\left(=S_{0}-S\right)$ is $\{E V[s(0), s(R)]-E V[s(0), s(R+\epsilon)]\} / \epsilon$, that is, the change in the equivalent variation associated with the incremental change in emissions reduction from $R$ to $R+\epsilon$, divided by $\epsilon$, where $\epsilon$ is arbitrarily small. In our experiments, $\epsilon$ is 0.1 million tons. Thus, for example, the marginal welfare cost associated with emissions reductions of 5 million tons is the change in the equivalent variation associated with augmenting the required abatement of emissions from 5.0 to 5.1 million tons, divided by 0.1 million tons.

${ }^{25}$ Taxes on labor include Federal and state income taxes and social security (payroll) taxes. Browning (1987, 1994) uses a value of 0.43 . 
abatement. The effect of the pre-existing tax on marginal costs (for either type of policy) is nonlinear. This squares with the fact that the tax-interaction effect rises in proportion to the marginal welfare cost of taxation, which rises approximately with the square of the initial tax rate.

Third, and perhaps most important, the marginal cost curve for the NRR policy has a positive intercept (except when the pre-existing tax rate is zero), while the curve for the RR policy has a zero intercept. Under RR policies, for an initial, incremental amount of pollution abatement, the tax-interaction effect is exactly offset by the revenue-recycling effect; hence the zero intercept. ${ }^{26}$ In contrast, under NRR policies, there is no offsetting revenue-recycling effect, and thus the intercept is positive.

The positive intercept carries some strong implications for policy. The intercept of the marginal cost curve represents a critical threshold value for the marginal environmental benefits (assuming such marginal benefits are constant or decreasing with the amount of sulfur dioxide abatement). If marginal environmental benefits are below this critical value, then no amount of emissions abatement through the NRR policy can be efficiency-improving! For example, according to Figure $2 \mathrm{~b}$ if the pre-existing labor tax is 0.4 the marginal benefits from $\mathrm{SO}_{2}$ abatement must be at least $\$ 109$ per ton to enable any quota policy to achieve an overall welfare gain. (Subsection IV.C below compares this threshold with a plausible range of estimates of marginal benefits from $\mathrm{SO}_{2}$ abatement.)

Within the range of emissions abatement shown in Figure 2, the marginal cost curves of NRR policies lie above the corresponding curves of RR policies, implying that NRR policies are more costly and generate smaller net benefits. Below we consider whether this applies over the entire possible range (from 0 to 100 percent) of emissions abatement.

\section{Significance of the Labor Supply Elasticity}

Figures $3 a$ and $3 b$ show that the costs of the RR and NRR policies are somewhat sensitive to the labor supply elasticity. These experiments assume a value of 0.4 for the pre-existing tax rate on labor. (Unless indicated otherwise, all simulations employ this "central case" value.) A higher labor supply elasticity implies more substitution with leisure, and hence a larger tax-interaction effect from emissionsabatement policies. The welfare gain from the revenue-recycling effect is also larger. Therefore, a higher

\footnotetext{
${ }^{26}$ The numerical model's nested utility function implicitly assumes that the consumption goods are equal substitutes for leisure. If this were not the case, the tax-interaction and revenue-recycling effects would not necessarily be equal at the initial incremental amount of abatement, and thus the intercept under the RR policy could be non-zero. These considerations do not affect the relative impacts of RR and NRR policies.
} 
labor supply elasticity raises costs by a greater amount under the NRR policy than under the RR policy. ${ }^{27}$

\section{Must the Polluting Sector Be "Large" for Second-Best Interactions to Be Significant?}

An important issue is the extent to which the relative costs of RR and NRR policies depend on the size of the polluting industry compared with the overall economy. To explore this issue, we run the numerical model under alternative, counterfactual assumptions about electricity's share of overall economic output. ${ }^{28}$ In particular, we consider counterfactual cases where electricity's output share is $0.5,2.0$ and 4.0 times its actual share in the U.S. economy. ${ }^{29}$ Results under these counterfactual cases are displayed in Figure 4. The size of the polluting sector makes very little difference to the results: the relative disadvantage of NRR policies (for a given relative amount of pollution abatement) applies independently of the size of the polluting sector. Even if the polluting sector's use of labor is a very small share of the economy's overall labor use, the interactions between environmental regulation and the labor market importantly affect the relative costs of RR and NRR policies. This is the case because the relative costs depend only on the relative magnitudes of the taxinteraction and revenue-recycling effects, not on their absolute magnitudes. ${ }^{30}$ Each of these effects increases roughly in proportion to the size of the polluting sector. Hence, the second-best issues we examine here seem important even in cases where the polluting industry is quite small relative to the rest of the economy.

\section{B. Relative Costs over the Entire Possible Range of Pollution Abatement}

In Figure 5 we display the relative costs of $R R$ and NRR policies over the range from 0 percent to

\footnotetext{
${ }^{27}$ The explanation is the same as that for the impact of the pre-existing tax rate. The tax-interaction effect increases more than proportionally with the marginal welfare cost of taxation, which is proportional to the elasticity of labor supply.
}

${ }^{28}$ In our baseline data set, the ratio of electricity gross output to economy-wide value added is approximately 0.04 , as indicated in Table 1 .

29 To do this, alter the benchmark data as follows. (In the benchmark, units are defined such that prices are one.) First, we multiply the elements $E_{E}, E_{0}, E_{C l}$ and $E_{C N}$ by a constant factor, and the elements $G_{E} G_{c}, G_{C I}$, and $G_{C N}$, by another constant factor, choosing the two factors so that net output (GDP) remains unchanged and electricity's share of net output $\left(\left(E_{\mathrm{E}}+\mathrm{E}_{\mathrm{G}}+\mathrm{E}_{\mathrm{Cl}}+\mathrm{E}_{\mathrm{CN}}\right) / \mathrm{GDP}\right)$ changes in the desired proportion. (GDP remains unchanged so long as the sum of the changed final demand components, $E_{C I}+E_{C N}+G_{C l}+G_{C N}$, is unchanged.) In addition, we reallocate value added (labor) across the $\mathrm{E}$ and $\mathrm{G}$ industries so that total receipts continue to equal total expenditures in these two industries. Total value added $-\mathrm{L}_{\mathrm{E}}+\mathrm{L}_{\mathrm{G}}$-- is unchanged. Thus, our procedure does not change GDP, whether measured as total final demand or total value added.

${ }^{30}$ This result may depend on the specification of demand and supply elasticities. In our model, these elasticities are constant over a wide range. This contributes to fairly constant relative magnitudes of the tax-interaction and revenue-recycling effects. 
100 percent abatement ( 20 million tons) of $\mathrm{SO}_{2}$ emissions. Figure 5 a shows that marginal abatement costs rise faster for the RR policies. Eventually -- when the extent of abatement is substantial -- marginal costs under RR policies exceed those of NRR. Why is this so? Consider the RR policy. Because of this policy's negative impact on labor supply and on emissions, marginal tax revenue declines as the emissions tax rate rises. This means that, with greater abatement, the ability to exploit the revenue-recycling effect diminishes. Eventually, one reaches a point where, at the margin, additional abatement (via an incrementally higher pollution tax) raises no more revenue than is raised under the NRR policy.

That is the point where the RR and NRR curves cross. ${ }^{31}$ To the right of that point, at the margin $\mathrm{RR}$ policies are more costly than NRR policies, because at the margin they have a negative revenue-recycling effect (as compared with the negligible revenue-recycling effect of the NRR policy). Indeed, if one pursues emissions reductions to the point of 100 percent abatement, the total costs of the two types of policies are identical. This makes sense, since at 100 percent abatement neither policy earns any revenue, and thus there is no effective difference between an RR and NRR policy. Thus the areas under the marginal cost curves from 0 to 100 percent abatement are the same for both policies. ${ }^{32}$

These results demonstrate that the relative superiority (in terms of lower cost) of RR policies diminishes with the extent of abatement. At low levels of abatement (as would be appropriate if marginal environmental benefits are low), RR policies have a considerable cost advantage. But at high levels of abatement (as would be justified when marginal environmental benefits are high) the advantage of RR policies is much smaller. In the limiting case of 100 percent abatement, $R R$ policies have no cost advantage These ideas are borne out by Figure $5 b$, which presents the ratio of total costs at different levels of emissions abatement. This ratio starts at infinity, but declines to 1 at 100 percent abatement.

In this connection it is noteworthy that the 1990 Clean Air Act Amendments call for a 10-million-ton reduction in $\mathrm{SO}_{2}$ emissions. These regulations fall in the NRR category, because emissions allowances are given out at no charge (grandfathered) rather than auctioned. There may be significant distributional or political objectives that are served by grandfathering, but, as indicated by Figure 5 b, they come at a high price in terms of cost. At 10 million tons of abatement, total costs under the NRR approach are 38 percent higher

\footnotetext{
${ }^{31}$ If the marginal revenue from the NRR policy were always zero, then the curves would cross where the RR policy's marginal revenue is zero as well. This zero-marginal-revenue point is the peak of the RR policy's Laffer curve. However, the NRR policy has some revenue impact, as discussed earlier, because of effects on the labor tax base and because it generates taxable rents. In Figure 5, the RR and NRR curves actually cross at a point where marginal revenue is slightly negative.

${ }^{32}$ We have experimented with other specifications for the abatement cost function, and we find this result holds in all cases.
} 
than they would be under an RR policy. The difference in costs is $\$ 560.5$ million. ${ }^{33}$

\section{Net Benefits from RR and NRR Policies}

We now consider environmental benefits in addition to the costs of regulation. Our purpose here is to illustrate differences in net benefits from $R R$ and NRR policies. As indicated above, the differences depend on the magnitudes of environmental benefits from emissions reductions. These marginal benefits are highly uncertain. For purposes of illustration, in calculating the net benefits we consider a wide range of values for the marginal benefits from emissions reductions: $\$ 100, \$ 250$, and $\$ 1000$ per ton. These values are consistent with the range of estimates reported in recent years. ${ }^{34}$

Table 2 indicates results under these alternative values. The first set of rows shows, for the RR policy, the optimal level of abatement corresponding to the different marginal benefit assumptions, along with the corresponding total abatement cost and net welfare gain (total environmental benefit minus total abatement cost). The second set of rows provides this same information for the NRR policy. Except when 100 percent abatement is justified, welfare gains are smaller under the NRR policy. For the low $(\$ 100$ per ton) value of marginal benefits, the net benefit or welfare gain under the NRR policy is zero, since optimal abatement is zero. In this case, any abatement through an NRR policy would be efficiency-reducing, since the marginal benefit is less than the intercept ( $\$ 109$ per ton) of the marginal cost function. With the intermediate value for the marginal environmental benefit, the optimal level of abatement under the NRR policy is again below that under the RR policy (since marginal abatement costs are higher under the NRR policy), and net benefits under the NRR policy are only about half of those under the RR policy. If marginal benefits are high ( $\$ 1000$ per ton), under both policies 100 percent abatement is optimal and (since the pollution tax in this case collects no revenue) total abatement costs are the same

An important issue is the extent to which optimal abatement in a second-best setting differs from the

\footnotetext{
${ }^{33}$ The costs of a 10-million-ton reduction are \$2052.7 and \$1492.2 million under the grandfathering (NRR) and auctioning (RR) of emissions allowances, respectively. Although this paper points out the efficiency drawbacks of the NRR element of $\mathrm{SO}_{2}$ emissions regulation under the 1990 Clean Air Act Amendments, it is not intended to be a wholesale critique of this legislation. We would note that the 1990 legislation achieved major reforms in environmental regulation by introducing a flexible, incentive-based approach to regulation in the form of emissions allowance trading. This approach has a number of theoretical advantages over the traditional, less flexible methods (see, for example, Tietenberg [1985]), and empirical studies already indicate that this approach will yield a dramatic reduction in overall compliance costs, compared to conventional approaches (see, for example, Burtraw [1996], and Ellerman and Montero [1996]).
}

${ }^{34}$ The range is approximately that implied in the overview by Portney (1990). Some more recent estimates exceed $\$ 1000$ per ton, due to greater predicted health benefits and an improved characterization of visibility benefits See USEPA (1995b) and Chestnut et al. (1994). 
first-best level. To examine this issue, we consider the level of abatement which would take place if, in determining the optimal level of abatement, regulators incorrectly identified firms' private marginal abatement costs with the social marginal costs of abatement. The level of abatement that results in this case is the same as the "Pigouvian" level -- that which equates firms' private marginal costs of abatement with the marginal benefits from emissions reduction. In a second-best setting with pre-existing taxes, the Pigouvian level of abatement is suboptimal because firms' private marginal costs of abatement do not correspond to the social marginal cost of abatement. The third set of rows gives the level of abatement that regulators would pursue if they ignored tax interactions and adopted a Pigouvian approach. That approach, by leading to excessive abatement, significantly reduces the welfare gains from regulation. Indeed, when marginal environmental benefits are low or moderate, regulations based on the Pigouvian approach, by disregarding the tax-interaction effect, can reduce welfare relative to the no-regulation status quo! The fourth panel of the table indicates, for example, that when (gross) marginal benefits of emissions reductions are $\$ 100$ per ton, introducing an emissions quota and setting the quota at the Pigouvian level generates a net welfare loss of $\$ 315.5$ billion, as opposed to a net gain of $\$ 169.8$ billion under the second-best optimal pollution tax policy. When marginal benefits are $\$ 221$ or below, excessive abatement under the Pigouvian approach leads to net welfare losses under the quota policy. When (gross) marginal benefits are $\$ 250$ per ton, the net welfare gain from the quota is only about 18 percent of the gain from the second-best optimal pollution tax.

Table 2 thus indicates the potential importance of interactions between environmental policies and other taxes. ${ }^{35}$ The welfare cost from failing to offset the tax-interaction effect through revenue-recycling can be substantial (panel 2 versus panel 1). In addition, there can be large costs from the excessive abatement that stems from adopting a first-best policy rule in a second-best setting (panels 3 or 4 versus panel 1 ).

\section{Further Sensitivity Analysis}

We have considered how pre-existing tax rates, labor supply elasticities, the size of the polluting sector, and the magnitude of marginal environmental benefits affect the relative costs and welfare gains of NRR and RR policies. In Table 3 we expand the sensitivity analysis to consider how other production and

${ }^{35}$ For further discussion of this issue see Parry (1996) and Oates (1995). A parallel result has recently emerged in the context of monopoly pricing: Browning (1995) estimates that the welfare loss from monopoly pricing in the U.S. economy is several orders of magnitude greater, once allowance is made for the effect of compounding tax distortions in the labor market. 
preference parameters, as well as alternative model specifications, might affect the relative costs of these two policies.

Higher elasticities of substitution in production mean that electricity (and associated $\mathrm{SO}_{2}$ emissions) can more easily be substituted for other intermediate inputs. Hence, marginal abatement costs fall with higher values for these parameters. The parameter $\sigma_{C}$ is the elasticity of substitution between the electricityintensive and non-electricity-intensive consumer goods. A higher value for this elasticity also implies lower social cost of avoiding electricity use; hence the social cost of avoiding $\mathrm{SO}_{2}$ emissions is lower as well.

The simulations reported thus far have assumed that quota-induced rents are taxed at the same rate as labor. The taxation of rents partly offsets the adverse revenue impact associated with the quota's negative impact on the labor tax base. Row 4 of the table presents results from simulations where quota rents are not taxed. In this circumstance there is no revenue offset, and the economy's marginal costs are higher at each level of abatement.

Rows 5a and 5b examine impacts of alternative values for the parameter $\alpha_{z}$ in the $\mathrm{SO}_{2}$ abatement function. A lower value for $\alpha_{z}$ means that a given amount of abatement equipment has a smaller effect on the emissions-output ratio, implying higher firm-level marginal abatement costs. Smaller values of $\alpha_{z}$ thus enlarge the tax-interaction effect and widen the differences in costs between RR and NRR policies, especially at lower levels of abatement.

Rows $6 \mathrm{a}$ and $6 \mathrm{~b}$ consider alternative model specifications. Results in row $6 \mathrm{a}$ are from a "collapsed" version of the numerical model that matches the analytical model. This version has no intermediate inputs and no separate abatement function. ${ }^{36}$ The marginal costs from this collapsed version correspond to the marginal costs predicted by equation (II.11") of the analytical model. ${ }^{37}$ By comparing results in rows 6 a with

\footnotetext{
${ }^{36}$ In this version of the numerical model, we treat $E$ and $G$ as consumer goods that are produced with the same production parameters as those for $C_{I}$ and $C_{N}$ in the original numerical model. Baseline $\mathrm{SO}_{2}$ emissions and consumption of $E$ and $G$ are the same as the original model's baseline levels for $\mathrm{SO}_{2}, C_{I}$ and $C_{N}$, respectively. We calibrate the utility function parameter $\sigma_{C}$ so that marginal abatement costs at 10 million tons of abatement are $\$ 300$ per ton, as in the original model.

${ }^{37}$ For the NRR policy, we the results in Table 3 with the marginal costs predicted by a modified version of equation (II.11"). Dividing this equation by $\partial X / \partial \tau_{x}$ gives the marginal Pigouvian and tax-interaction effects. Adding $D$ to the resulting expression eliminates the marginal environmental benefit component of overall welfare impact, yielding the residual, $\tau_{X}-\left(I+M^{\prime}\right) \tau_{L}(\partial \ell / \partial X)$, which stands for marginal cost. The first term $\left(\tau_{X}\right)$ is the firm-level marginal cost of abatement; the second term is the marginal tax-interaction effect. With the numerical model, we obtain each element in this formula, and then apply the formula to calculate predicted marginal costs. Doing so gives marginal costs of $\$ 138.6, \$ 222.6$, and $\$ 339.4$ million, at 0,5 , and 10 million tons of abatement, respectively. These predicted marginal costs are within one percent of Table 3's marginal costs, which were obtained directly from the equivalent variation measure of the changes in household utility associated with incremental changes in abatement.
} 
those in row 1 for the RR policy and row 4 for the NRR policy, ${ }^{38}$ we can observe the importance of intermediate inputs and a separate abatement function. For both types of policies, marginal costs (and the tax-interaction effect) are lower in the original model than in the scaled-down model. Intermediate inputs and a separate abatement function expand the opportunities for emissions abatement and lower the costs of achieving given emissions reductions.

Row $6 \mathrm{~b}$ presents results from a more disaggregated version of the numerical model that contains coal and "other fuels" as intermediate inputs, in addition to $G$ and $E$. In the original numerical model the abatement function linked $\mathrm{SO}_{2}$ emissions with electricity output (as well as abatement expenditure); the expanded model's greater disaggregation enables us to use a more realistic abatement function relating emissions to the level of coal input in the electricity industry. ${ }^{39}$ This model specification leads to somewhat lower marginal costs than in the original specification, in keeping with the widened opportunities for input substitution.

A further potential area for sensitivity analysis deserves mention. We have assumed that emissions (or environmental quality) are separable from consumption or leisure in utility. Relaxing this assumption would affect the results. If environmental quality and leisure are gross complements, then regulations improving the environment will generate a larger tax-interaction effect, other things equal, because policies' adverse impacts on labor supply will be magnified. The reverse is true if leisure and environmental quality are gross substitutes. The case of gross complements seems more likely, since a cleaner environment can make leisure or recreational activities more attractive. Further empirical work that helps identify these relationships would be of considerable value to policy makers.

\section{Conclusions}

Using analytical and numerical general equilibrium models, this paper indicates that the taxinteraction effect -- the factor market impact of environmental regulations imposed in markets for produced goods -- may critically influence the efficiency consequences of environmental regulations. In a world with

${ }^{38}$ Row 4 is the appropriate row to consider for the quota policy since the analytical model's formulas assume no taxes on quota rents.

${ }^{39}$ In the expanded version, $X_{z}$ (electricity output) in the abatement cost function is replaced by $x_{\text {coal }, B}$, the use of coal by the electricity industry. We calibrate $\alpha_{S}$ to yield the same baseline emissions as in the original model, and calibrate $\alpha_{z}$ yield marginal abatement costs of $\$ 300$ per ton at 10 million tons of $\mathrm{SO}_{2}$ emissions. 
prior taxes on factors, the tax-interaction effect implies significantly higher costs of regulation relative to what would apply in a first-best world with no pre-existing taxes. Revenue-raising regulations enjoy a revenue-recycling effect that offsets much of the tax-interaction effect. Non-revenue-raising regulations, in contrast, enjoy no such offset. As a result, for any given target level of emissions reduction, the gross efficiency costs of non-revenue-raising policies are higher than those of revenue-raising policies. The differences in gross efficiency costs are not trivial. U.S. environmental regulations enforce reductions of about ten million tons in $\mathrm{SO}_{2}$ emissions from coal-fired electric power plants. Our calculations suggest that because these regulations do not raise revenue (emissions allowances are grandfathered) the gross social costs of these regulations are approximately 38 percent higher than they would be if emissions allowances were auctioned.

In fact, the sign of the welfare impact of environmental regulations can depend on whether policies raise revenue. If marginal environmental benefits fail to exceed a critical threshold value, any pollution abatement through an NRR policy is efficiency-reducing. In the context of $\mathrm{SO}_{2}$ emissions regulation in the U.S., we find that under an NRR policy (as with grandfathered emissions allowances) the efficiency gains disappear entirely if marginal environmental benefits are below $\$ 109$ per ton. In addition, we show that adopting a "Pigouvian" or first-best approach to environmental regulation can lead to welfare-reducing policies, even when environmental benefits are as high as \$221 per ton. The disadvantage of NRR policies relative to RR policies shrinks the larger the marginal environmental benefits and the larger the optimal amount of abatement. In the limiting case where environmental benefits justify 100 percent abatement, there is no difference in welfare impacts of NRR and RR policies. All of these results are largely independent of the size of the polluting or regulated sector relative to the overall economy.

These insights have very general applicability. They suggest that almost any government regulation that lowers real factor returns (by raising the price of consumer goods) might have considerably higher aggregate cost than would be implied by a partial equilibrium analysis. Existing studies in industrial organization, agricultural economics, labor economics and international trade could be highly misleading to the extent that they evaluate regulatory policies using models that disregard pre-existing tax distortions. 


\section{References}

Auerbach, A.J., 1985, The theory of excess burden and optimal taxation, in A.J. Auerbach and M.S. Feldstein (eds.), Handbook of Public Economics, Vol. 1, North-Holland, Amsterdam.

Ballard, Charles, L., John B. Shoven, and John Whalley, 1985. "General Equilibrium Computations of the Marginal Welfare Costs of Taxes in the U.S." American Economic Review 75(1):128-38.

Ballard, Charles L., and Steven G. Medema, 1993. "Distortionary Taxes and the Provision of Public Goods." Journal of Public Economics 52:199-216.

Bovenberg, A. Lans, and Ruud A. de Mooij, 1994. "Environmental Levies and Distortionary Taxation." American Economic Review 84(4):1085-9.

Bovenberg, A. Lans, and Lawrence H. Goulder, 1996. "Optimal Environmental Taxation in the Presence of Other Taxes: General Equilibrium Analyses." American Economic Review, forthcoming.

Bovenberg, A. Lans, and F. van der Ploeg, 1994.. "Environmental Policy, Public Finance and the Labour Market in a Second-Best World." Journal of Public Economics 55:349-90.

Browning, E. K., 1994. “The Non-Tax Wedge.”Journal of Public Economics 53:419-433.

Browning, E. K., 1995. "The Welfare Cost of Monopoly and Other Output Distortions." Working Paper, Department of Economics, Texas A\&M University.

Browning, E. K., 1987. "On the Marginal Welfare Cost of Taxation." American Economic Review 77:1123.

Burtraw, Dallas, 1996. "The $\mathrm{SO}_{2}$ Emissions Trading Program: Cost Savings Without Allowance Trades," Contemporary Economic Policy, vol. XIV, no. 2 (April), 79-94.

Burtraw, Dallas, Winston Harrington, Alan J. Krupnick, and Myrick Freeman III, 1995. "Optimal 'Adders' for Environmental Damage by Public Utilities." Journal of Environmental Economics and Management 29(3):S1-S19, November.

Chestnut, Lauraine G., Robin L. Dennis and Douglas A. Latimer. 1994. "Economic Benefits of Improvements in Visibility: Acid Rain Provisions of the 1990 Clean Air Act Amendments," Proceedings of the International Specialty Conference, Aerosols and Atmospheric Optics, Volume A, Air \& Waste Management Association.

Cruz, Miguel and Lawrence H. Goulder, 1992. "An Intertemporal General Equilibrium Model for Analyzing U.S. Energy and Environmental Policies: Data Documentation." Unpublished manuscript, Stanford University.

Electric Power Research Institute (EPRI), 1995. The Emission Allowance Market and Electric Utility $\mathrm{SO}_{2}$ Compliance in a Competitive and Uncertain Future, TR-105490, prepared by K. White, Energy Ventures Analysis, Inc., and Van Hom Consulting, Palo Alto, CA (Final Report: September). 
Ellerman, A. Denny, and Juan Pablo Montero, 1996. "Why Are Allowance Prices So Low? An Analysis of the $\mathrm{SO}_{2}$ Emissions Trading Program," CEEPR 96-001, Massachusetts Institute of Technology (February)

Goulder, Lawrence H., 1995. "Environmental Taxation and the 'Double Dividend': A Reader's Guide." International Tax and Public Finance 2(2):157-183.

Hahn, Robert W., 1986. “Trade-offs in Designing Markets with Multiple Objectives." Journal of Environmental Economics and Management 13:1-12.

Lee, Dwight R., and Walter S. Misiolek, 1986. "Substituting Pollution Taxation for General Taxation: Some Implications for Efficiency in Pollution Taxation." Journal of Environmental Economics and Management 13:338-347.

Ng, Y. K., 1980. "Optimal Corrective Taxes or Subsidies when Revenue-Raising Imposes an Excess Burden." American Economic Review 70:744-51.

Nichols, Albert L., 1984. Targeting Economic Incentives for Environmental Protection. Cambridge, Mass.: MIT Press.

Oates, Wallace E., 1993. "Pollution Charges as a Source of Public Revenues." In Herbert Giersch, ed., Economic Progress and Environmental Concerns. Berlin: Springer-Verlag, pp. 135-52.

Oates, Wallace E., 1995. "Green Taxes: Can We Protect the Environment and Improve the Tax System at the Same Time?" Southern Economic Journal 61(4):914-922.

Oates, Wallace E., and Robert M. Schwab, 1988. “Economic Competition among Jurisdictions: Efficiency Enhancing or Distortion Inducing?" Journal of Public Economics 35:333-354, April.

Parry, Ian W. H., 1995. "Pollution Taxes and Revenue Recycling." Journal of Environmental Economics and Management 29:S64-S77.

Parry, Ian W. H., 1996. "Environmental Taxes and Quotas in the Presence of Distorting Taxes in Factor Markets." Resource and Energy Economics, forthcoming.

Portney, Paul R, 1990. "Economics and the Clean Air Act." Journal of Economic Perspectives 4(4):173181 , Fall.

Poterba, James M., 1993. "Global Warming: A Public Finance Perspective." Journal of Economic Perspectives 7(4), 47-63.

Repetto, Robert, Roger C. Dower, Robin Jenkins, and Jacqueline Geoghegan, 1992. Green Fees: How a Tax Shift Can Work for the Environment and the Economy. World Resources Institute, November.

Resource Data International, Inc., 1995. RDI's Phase I 1995 Databook Performance Under the Clean Air Act Amendments of 1990. Boulder, CO. (Autumn).

Sandmo, Agnar, 1975. "Optimal Taxation in the Presence of Externalities." Swedish Journal of Economics 77. 
Shackleton, Robert, Michael Shelby, Alex Cristofaro, Roger Brinner, Joyce Yanchar, Lawrence Goulder, Dale Jorgenson, Peter Wilcoxen, and Peter Pauly, 1996. "The Efficiency Value of Carbon Tax Revenues." In Darius Gaskins and John Weyant, eds., Reducing Global Carbon Dioxide Emissions: Costs and Policy Options. Forthcoming, Stanford University Press.

Shoven, John B., and John Whalley, 1992. Applying General Equilibrium. Cambridge, Mass.: Cambridge University Press.

Stavins, Robert, ed, 1991. Project 88--Round II, Incentives for Action: Designing Market-Based Environmental Strategies. Public policy study sponsored by Senators Timothy Wirth and John Heinz, Washington, D.C., May.

Terkla, David, 1984. "The Efficiency Value of Effluent Tax Revenues." Journal of Environmental Economics and Management 11:107-23.

Tietenberg, T. H. 1985. Emissions Trading: An Exercise In Reforming Pollution Policy. Washington D.C.: Resources for the Future.

U.S. Environmental Protection Agency (USEPA), 1995a. "Economic Analysis of The Title IV Requirements of the 1990 Clean Air Act Amendments," prepared by ICF Resources Incorporated, Washington D.C. (Final Report: September).

U.S. Environmental Protection Agency (USEPA), 1995b. Human Health Benefits from Sulfate Reductions under Title $V$ of the 1990 Clean Air Act Amendments, prepared by . prepared by Lauraine, G. Chestnut (Contract No. 68-D3-0005).

U.S. National Acid Precipitation Assessment Program (NAPAP), 1991. 1990 Integrated Assessment Report, Washington D.C.

Weitzman, Martin L., 1974. "Prices vs. Quantities." Review of Economic Studies 41:477-491. 


\section{Appendix A: Deriving Equation (II.13)}

From (II. 12)

(Al) $\quad 1+M=M\left\{\frac{T-l+D \frac{\partial X}{\partial \tau_{L}}}{\tau_{L} \frac{\partial l}{\partial \tau_{L}}+\left(D-\tau_{X}\right) \frac{\partial X}{\partial \tau_{L}}}\right\}$

and from the Slutsky equations

$$
\frac{\partial l}{\partial \tau_{X}}=\frac{\partial l^{c}}{\partial \tau_{X}}-\frac{\partial l}{\partial I} X
$$

$$
\frac{\partial l}{\partial \tau_{L}}=\frac{\partial l^{c}}{\partial \tau_{L}}-\frac{\partial l}{\partial I}(T-l)
$$

where $c$ denotes a compensated coefficient and $I$ is disposable income. Substituting (Al)-(A3) in the expression for $\partial W^{l}$ in (II.11) gives

$$
\partial W^{I}=\frac{M\left\{\tau_{L}\left(\frac{\partial l^{c}}{\partial \tau_{X}}-\frac{\partial l}{\partial I} X\right)\left(T-l+D \frac{\partial X}{\partial \tau_{L}}\right)\right\}}{\tau_{L}\left(\frac{\partial l^{c}}{\partial \tau_{L}}-\frac{\partial l}{\partial I}(T-l)\right)+\left(D-\tau_{X}\right) \frac{\partial X}{\partial \tau_{L}}}
$$

From the Slutsky symmetry property $\frac{\partial l^{c}}{\partial \tau_{X}}=-\frac{\partial X}{\partial \tau_{L}} \cdot{ }^{1}$ Differentiating (II.2) yields:

$$
\begin{aligned}
& \frac{\partial l^{c}}{\partial \tau_{L}}=-\left(\frac{\partial X^{c}}{\partial \tau_{L}}+\frac{\partial Y^{c}}{\partial \tau_{L}}\right) . \text { Making these substitutions in (A4) gives } \\
& \partial W^{I}=\frac{M X\left\{\left[\frac{\partial X^{c}}{\partial \tau_{L}} \frac{1-\tau_{L}}{X}+\frac{\partial l}{\partial I} \frac{\left(1-\tau_{L}\right)(T-l)}{T-l}\right]\left[1+\frac{\partial X}{\partial \tau_{L}} \frac{1-\tau_{L}}{X} \frac{D X}{\left(1-\tau_{L}\right)(T-l)}\right]\right\}}{\left\{\frac{\partial X^{c}}{\partial \tau_{L}} \frac{1-\tau_{L}}{X} \frac{X}{T-l}+\frac{\partial Y^{c}}{\partial \tau_{L}} \frac{1-\tau_{L}}{Y} \frac{Y}{T-l}+\frac{\partial l}{\partial I} \frac{\left(1-\tau_{L}\right)(T-l)}{T-l}\right\}-\frac{\partial X}{\partial \tau_{L}} \frac{\left(1-\tau_{L}\right)}{X} \frac{\left(D-\tau_{X}\right) X}{\tau_{L}(T-l)}}
\end{aligned}
$$

${ }^{1}$ Note that increasing $\tau_{X}$ increases the price of $X$, while increasing $\tau_{L}$ reduces the price of leisure. 
Substituting $\eta_{X I}^{c}=-\frac{\partial X^{c}}{\partial \tau_{L}} \frac{1-\tau_{L}}{X} ; \eta_{Y l}^{c}=-\frac{\partial Y^{c}}{\partial \tau_{L}} \frac{1-\tau_{L}}{Y} ; \eta_{L}=-\frac{\partial l}{\partial I} \frac{\left(1-\tau_{L}\right)(T-l)}{T-l}$; $\eta_{X I}=-\frac{\partial X}{\partial \tau_{L}} \frac{1-\tau_{L}}{X} ;$ and (II.2), gives

$$
\partial W^{I}=\frac{M X\left\{\eta_{X I}^{c}+\eta_{L}\right\}\left\{1-\eta_{X I}\left(\frac{D X}{\left(1-\tau_{L}\right)(T-l)}\right)\right\}}{\left\{\eta_{X X}^{c}\left(\frac{X}{X+Y}\right)+\eta_{Y I}^{c}\left(\frac{Y}{X+Y}\right)+\eta_{L}\right\}-\eta_{X} \frac{\left(D-\tau_{X}\right) X}{\tau_{L}(T-l)}}
$$

The term in $\eta_{X L}$ in the numerator is trivial when environmental damages from $X$ are small relative to aggregate net labor income in the economy, and the term in $\eta_{x z}$ in the denominator is trivial when environmental damages net of environmental tax revenues is small relative to aggregate labor tax revenues Hence the approximation in (II.13) 


\section{Appendix B: The Numerical Model}

\section{A. Parameters}

(Note: except where otherwise specified, $i$ ranges over industries $G, E, C_{l}$, and $C_{N}$

\section{Production Function Parameters}

$\alpha_{m i} \quad$ distribution parameter for input $m$ in industry $i$

$\rho_{\mathrm{i}} \quad$ substitution parameter for industry $i$

Abatement Function Parameters

$\alpha_{s}, \alpha_{z}$

$\beta$ parameters for sulfur abatement function for electricity firms

Household-Related Parameters

$T \quad$ total time endowment

$\alpha_{\ell}, \alpha_{\bar{C}}$

$\alpha_{C I}, \alpha_{C N}$

distribution parameters for utility function

$\rho_{U}, \rho_{\bar{C}}$ substitution parameters for utility function

\section{Other Parameters}

$\begin{array}{ll}\tau_{L 0} & \text { initial marginal tax rate on labor income or rents } \\ \tau_{S} & \text { per-unit tax on emissions of } S \\ S & \text { aggregate sulfur dioxide emissions target } \\ T R & \text { real lump-sum transfers to households (fixed in real terms) }\end{array}$

\section{B. Endogenous Variables}

$\begin{array}{ll}a_{m i} & \text { use of input } m \text { per unit of output of good } i \\ C_{I} & \text { quantity demanded of electricity-intensive consumption good } \\ C_{N} & \text { quantity demanded of non-electricity-intensive consumption good } \\ \bar{C} & \text { quantity demanded of composite consumption good } \\ E & \text { aggregate supply of electricity } \\ E_{-} A D & \text { aggregate demand for electricity } \\ G & \text { aggregate supply of general intermediate good } \\ G A D & \text { aggregate demand for general intermediate good } \\ L_{-} & \text {aggregate labor supply } \\ L_{-} A D & \text { aggregate labor demand }\end{array}$




$\begin{array}{ll}p_{\bar{C}} & \text { price of composite consumption good } \\ p_{i} & \text { price of output from industry } i \\ p_{L} & \text { price of labor (before tax) } \\ R E N T & \text { total rent eamed by electricity producers } \\ R E V & \text { government revenue } \\ S_{j} & \text { sulfur dioxide emissions by electricity producer } j \\ U & \text { overall household utility } \\ V & \text { utility associated with level of sulfur emissions } \\ X_{i} & \text { output from industry } i \\ x_{j i} & \text { use of input } j \text { by industry } i \\ Z_{j} & \text { abatement equipment purchased by electricity producer } j \\ \Delta \tau_{L} & \text { change in marginal tax on labor income } \\ \pi_{j} & \text { rent earned by electricity producer } j\end{array}$

\section{Equations}

\section{Production Functions and Optimal Input Intensities}

In all industries, output $(X)$ is produced according to:

$$
X_{i}=\left(\alpha_{L i} x_{L i}^{\rho_{i}}+\alpha_{E i} x_{E i}^{\rho_{i}}+\alpha_{G i} x_{G i}^{\rho_{i}}\right)^{\frac{1}{\rho_{i}}} \quad\left(i=G, E, C_{I}, C_{N}\right)
$$

-- General Intermediate Good and Consumer Goods Industries:

In the $G, C_{l}$, and $C_{N}$ industries, profit is given by $p_{X} X_{i}-p_{L} x_{L i}-p_{E} x_{E i}-p_{G} x_{G i}$. Differentiating profit with respect to the variable inputs $x_{m i}(m=L, E, G)$ yields the marginal productivity condition, $p_{i} \partial X_{i} / \partial x_{m i}$ $=p_{m}$ ). Evaluating this condition with the functional form in (BI) yields the optimal input intensities:

$$
a_{m i} \equiv \frac{x_{m i}}{X_{i}}=\alpha_{m i}^{\frac{1}{1-\rho_{i}}}\left(\frac{p_{m}}{p_{i}}\right)^{-\frac{1}{1-\rho_{i}}}
$$

for $m=L, E, G$

-- Electricity Industry:

In the electricity $(E)$ industry, firms choose optimal input levels not only of $L, G$, and $E$, but also the optimal level of expenditure on abatement equipment $(Z)$. We first indicate optimal input and abatement choices where the firm faces a pollution tax. We will then show that the firm's optimal choices under a pollution quota are the same as under the pollution tax, which enables us to model the pollution quota as a 
pollution tax with revenues retained as rents to the firm. ${ }^{1}$ For a representative firm in the electricity industry, profit is given by:

$$
\pi_{E}=p_{E} X_{E}-p_{L} x_{L E}-p_{G} x_{G E}-p_{E} x_{E E}-p_{Z} Z-\tau_{S} S
$$

where $p_{L} p_{E}$, and $p_{G}$ represent the prices of inputs of labor, electricity, and the general intermediate input, respectively. $Z$ and $S$ represent abatement equipment or services and $\mathrm{SO}_{2}$ emissions, respectively; $p_{Z}$ is the unit price of abatement equipment or services (assumed to be equal to the price of labor) and $\tau_{\mathrm{s}}$ is the tax rate on $\mathrm{SO}_{2}$ emissions.

The relationship between electricity output, pollution emissions, and abatement equipment is:

$$
S / X_{E}=\alpha_{S}-\alpha_{Z}\left(Z / X_{E}\right)^{\beta}
$$

The ratio of $S$ to electricity output is a decreasing function of $Z$, the quantity of abatement services or equipment employed.

Electricity producers maximize profits subject to to (B4). Substituting the production function (B1) and the $\mathrm{SO}_{2}$ emissions function (B4) into (B3) and differentiating by the choice variables $x_{L E}, x_{G E}, x_{E E}$, and $Z$ yields the first-order conditions:

$$
\begin{aligned}
& a_{L E} \equiv x_{L E} / X_{E}=\left[\alpha_{L E}+\alpha_{E E}\left(\frac{p_{E} \alpha_{L E}}{p_{L} \alpha_{E E}}\right) \frac{\rho_{E}}{\rho_{E}-1}+\alpha_{G E}\left(\frac{p_{G} \alpha_{L E}}{p_{L} \alpha_{G E}}\right) \frac{\rho_{E}}{\rho_{E}-1}\right]^{-1 / \rho_{E}} \\
& a_{G E} \equiv x_{G E} / X_{E}=a_{L E}\left(\frac{p_{G} \alpha_{L E}}{p_{L} \alpha_{G E}}\right) \frac{1}{\rho_{E}-1} \\
& a_{E E} \equiv x_{E E} / X_{E}=a_{L E}\left(\frac{p_{E} \alpha_{L E}}{p_{L} \alpha_{E E}}\right) \frac{1}{\rho_{E}-1}
\end{aligned}
$$

The equivalence to firm behavior between the virtual tax and the quota can be seen as follows. Under the pollution quota, the firm's profit function is

${ }^{1}$ Pollution quotas are implemented by the government's giving a fixed number of pollution permits to existing firms. Since rents are enjoyed only by furms with permits and the number of permits is fixed, the existence of rents does not trigger further entry. 


$$
\pi_{E}=p_{E} X_{E}-p_{L} x_{L E}-p_{G} x_{G E}-p_{E} x_{E E}-p_{Z} Z
$$

Firms maximize (B6) subject to the constraint imposed by the quota:

$$
X_{E}\left[\alpha_{S}-\alpha_{Z}\left(Z / X_{E}\right)^{\beta}\right]=S
$$

where $\bar{S}$ represents the emissions quota. The Lagrangean expression corresponding to this maximization problem is:

$$
\mathscr{L}=p_{E} X_{E}-p_{L} x_{L E}-p_{G} x_{G E}-p_{E} x_{E E}-p_{Z} Z-\lambda\left\{X_{E}\left[\alpha_{S}-\alpha_{Z}\left(Z / X_{E}\right)^{\beta}\right]-\bar{S}\right\}
$$

Let the (virtual) pollution tax be set equal to $\lambda$, the shadow price on the emissions constraint. In this case, the Lagrangean expression is identical to the maximization problem under the pollution tax case, except for the constant $\tau_{s} \bar{S}$. Thus the first-order conditions from this maximization problem are the same as those under the pollution tax, implying that firms' behavior under the pollution quota can be modeled through a virtual pollution tax. Under the virtual tax, the firm regards and responds to the tax as if it is a cost, but in fact the tax "revenues" are rebated as rents to the firm.

Household Utility Function, Labor Supply and Consumer Good Demands

The representative household's utility function is:

$$
U=\left(\alpha_{\ell} \ell^{\rho_{u}}+\alpha_{\bar{C}} \bar{C}^{\rho_{u}}\right)^{\frac{1}{\rho_{u}}}+V(S)
$$

where $\ell$ is leisure and $\bar{C}$ is composite consumption, given by

$$
\bar{C}=\left(\alpha_{C_{I}} C_{I}^{\rho_{\bar{C}}}+\alpha_{C_{N}} C_{N}^{\rho_{\bar{C}}}\right)^{\frac{1}{\rho_{\bar{C}}}}
$$

The household's budget constraint is:

$$
\begin{aligned}
P_{C I} C_{I} & +P_{C N} C_{N}=P_{L}\left(1-\tau_{L}\right)(T-\ell) \\
& +\left(1-\tau_{R}\right) R E N T+T R
\end{aligned}
$$


where $\tau_{L}$ is the marginal tax rate on labor, $T$ is total labor time (thus $L=T-\ell$ ), RENT is the total rent equal by electricity firms, and TR is a lump-sum transfer from the public sector. Equations (B12-B17) express the solution the household's maximization problem:

$$
a_{I \bar{C}}=\left[\alpha_{C I}+\alpha_{C N}\left(\frac{\alpha_{C I} p_{C N}}{\alpha_{C N} p_{C I}}\right)^{\frac{\rho_{\bar{C}}}{\rho_{\bar{C}}-1}}\right]^{\frac{1}{\rho_{\bar{C}}}}
$$

$$
a_{N \bar{C}}=\left[\alpha_{C N}+\alpha_{C I}\left(\frac{\alpha_{C N} p_{C I}}{\alpha_{C I} p_{C N}}\right)^{\frac{\rho_{\bar{c}}}{\rho_{\bar{C}-1}}}\right]^{\frac{1}{\rho_{\bar{C}}}}
$$

$$
p_{\bar{C}}=p_{C I} a_{I \bar{C}}+p_{C N} a_{N \bar{C}}
$$

$$
\ell=\frac{p_{L}\left(1-\tau_{L}\right) T+T R+\left(1-\tau_{R}\right) R E N T}{p_{L}\left(1-\tau_{L}\right)+\left[\frac{\alpha_{\ell} p_{\bar{C}}}{\alpha_{\bar{C}} p_{L}\left(1-\tau_{L}\right)}\right]^{\frac{1}{p_{L}-1}} p_{\bar{C}}}
$$

(B16) $L=T-\ell$

$$
\bar{C}=\left(p_{\bar{C}}\right)^{-1}\left[p_{L}\left(1-\tau_{L}\right) L+\left(1-\tau_{R}\right) R E N T+T R\right]
$$

Combining (B17) with (B12) or (B13) yields the optimal levels of $C_{J}$ and $C_{N}$.

\section{The Government Sector}

Government revenues finance a fixed level of real government transfers, $T R$. Revenues (REV) depend on whether the policy is an actual emissions tax $\left(\tau_{s}{ }^{\circ}\right)$ or an emissions quota (virtual tax, $\left.\tau_{s}{ }^{\nu}\right)$. Under the pollution tax policy, revenues are:

$$
R E V=\tau_{L} L+\tau_{S}{ }^{a} S
$$


where $\tau_{\mathrm{L}}$ is the tax rate on labor income, and $S$ is aggregate sulfur dioxide emissions. Under the emissions quota policy, revenues are:

$$
R E V=\tau_{L} L+\tau_{R} R E N T
$$

where RENT equals $\tau_{s}^{v} S$ and denotes the total rent generated by the quota.

Under all policies, the tax on labor is equal to the initial tax rate plus $\Delta \tau_{L}$, the rate change necessary to yield total revenues equal to the given level of spending (fixed real transfers). Thus:

$$
\tau_{L}=\tau_{L o}+\Delta \tau_{L}
$$

For simplicity we usually assume that rents are taxed at the same rate as is labor income: $\tau_{R}=\tau_{L}$.

Prices (other than primary prices ${ }^{2}$ )

$$
\begin{aligned}
& p_{C I}=a_{L C I} p_{L}+a_{E C I} p_{E}+a_{G C I} p_{G} \\
& p_{C N}=a_{L C N} p_{L}+a_{E C N} p_{E}+a_{G C N} p_{G} \\
& p_{G}=a_{L G} p_{L}+a_{E G} p_{E}+a_{G G} p_{G} \\
& p_{E}=a_{L E} p_{L}+a_{E E} p_{E}+a_{G E} p_{G}+p_{Z}\left(Z / X_{E}\right)+\tau_{S}\left(S / X_{E}\right)
\end{aligned}
$$

The electricity price $p_{E}$ equals unit input cost (first three terms) plus unit abatement expenditure (fourth) term plus whatever tax costs or rents may apply. The last term in (B24) represents the unit tax cost in the pollution tax case and the unit rent in the quotas case.

\section{Aggregate Supplies and Demands}

-- aggregate supplies and demands of intermediate goods:

Since production of the general intermediate good and electricity follows constant returns to scale, the supplies $G$ and $E$ are demand-determined. Thus $X_{G}=G_{-} A D$ and $X_{E}=E \_A D$, where $G A D$ and $E \_A D$ denote the aggregate demands. The aggregate demands for $\bar{G}$ and $E$ are expressed by:

\footnotetext{
${ }^{2}$ See section $D$ below for definition of primary prices.
} 
(B25)

$$
G \_A D=a_{G S} X_{G}+a_{G E} X_{E}+a_{G I} C_{l}+a_{G N} C_{N}
$$

(B26) $\quad E \_A D=a_{E O} X_{G}+a_{E E} X_{E}+a_{E I} C_{I}+a_{E N} C_{N}$

Equations (B25 and (B26) are solved simultaneously to obtain $G_{-} A D$ and $E \_A D$

-- aggregate demand for labor $\left(L_{-} A D\right)$.

$$
L \_A D=a_{L G} G A D+a_{L E} E_{-} A D+Z+a_{L L} C_{I}+a_{L N} C_{N}
$$

\section{Equilibrium Conditions}

The equilibrium conditions are:

(B28) $\begin{array}{rll}L_{-} A D & = & L \\ S & = & S \\ R E V & = & T R\end{array}$

Solution of the model involves finding the vector of primary "prices" satisfying the equilibrium conditions. These prices uniquely determine all quantities and other prices of the system. The primary prices are $p_{L}, \tau_{s}$, and $\Delta \tau_{L}$. We use $p_{L}$ as the numeraire and solve explicitly only for the latter two primary prices. By Walras's Law, one of the equilibrium conditions is redundant: we need only apply the latter two equilibrium conditions to determine $\tau_{S}$, and $\Delta \tau_{L}$. 
Figure 1

Input Types and Uses in the Numerical Model

uses of inputs

$\begin{array}{lllll}E & G & C_{I} & C_{N} & \ell\end{array}$

inputs

\begin{tabular}{|c|c|c|c|c|c|}
\hline & $E$ & $G$ & $C_{I}$ & $C_{N}$ & $\ell$ \\
\hline$E$ & $\mathbf{x}_{\mathrm{EE}}$ & $\mathbf{x}_{\mathrm{EG}}$ & $\mathbf{x}_{\mathrm{EI}}$ & $\mathbf{x}_{\mathrm{EN}}$ & \\
\hline$G$ & $\mathbf{x}_{\mathrm{GE}}$ & $\mathbf{x}_{\mathrm{GG}}$ & $\mathbf{x}_{\mathrm{GI}}$ & $\mathbf{x}_{\mathrm{GN}}$ & \\
\hline$L$ & $\mathbf{x}_{\mathrm{LE}}$ & $\mathbf{x}_{\mathrm{LG}}$ & $\mathbf{x}_{\mathrm{LI}}$ & $\mathbf{x}_{\mathrm{LN}}$ & $\ell$ \\
\hline$S$ & $S$ & & & & \\
\hline
\end{tabular}




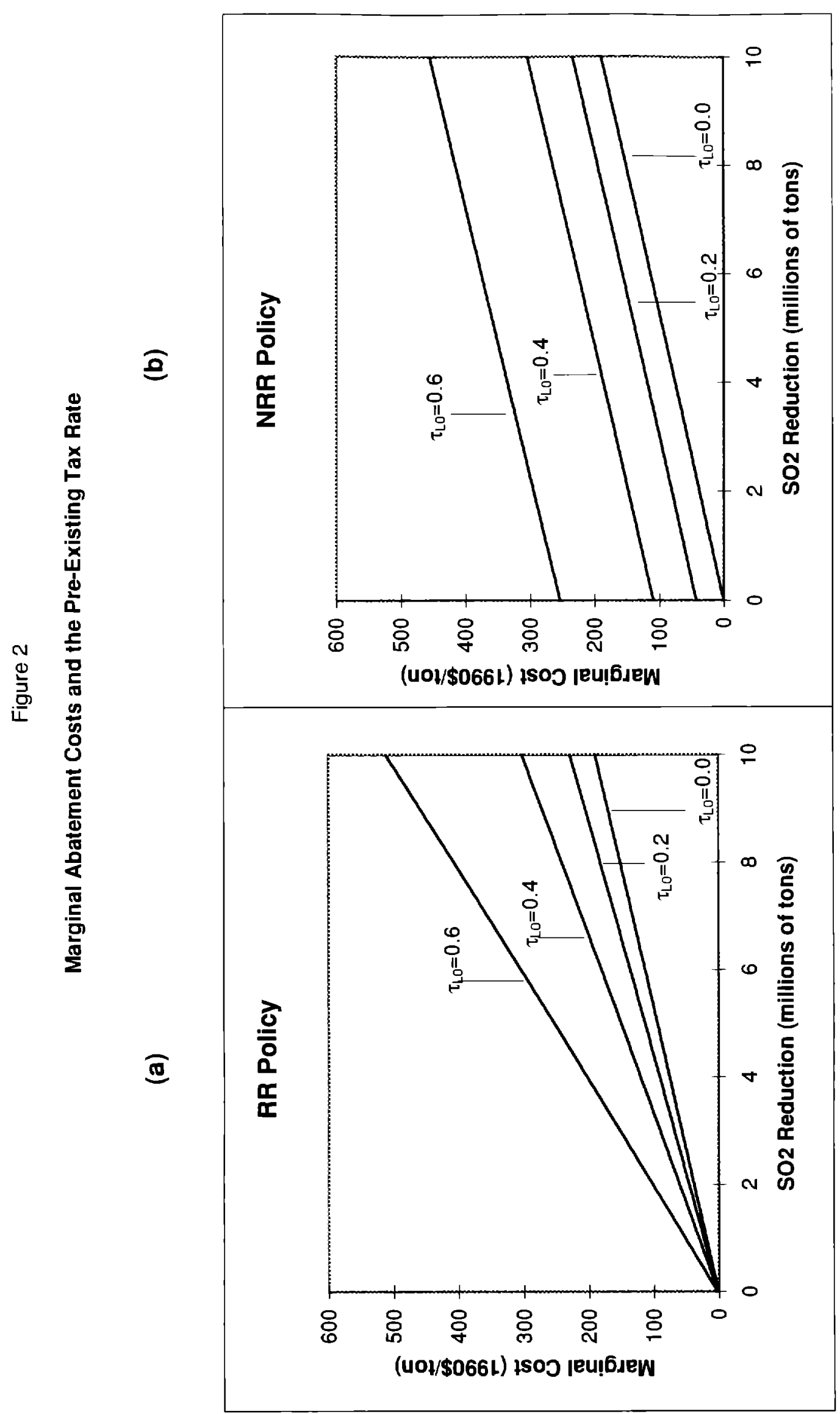




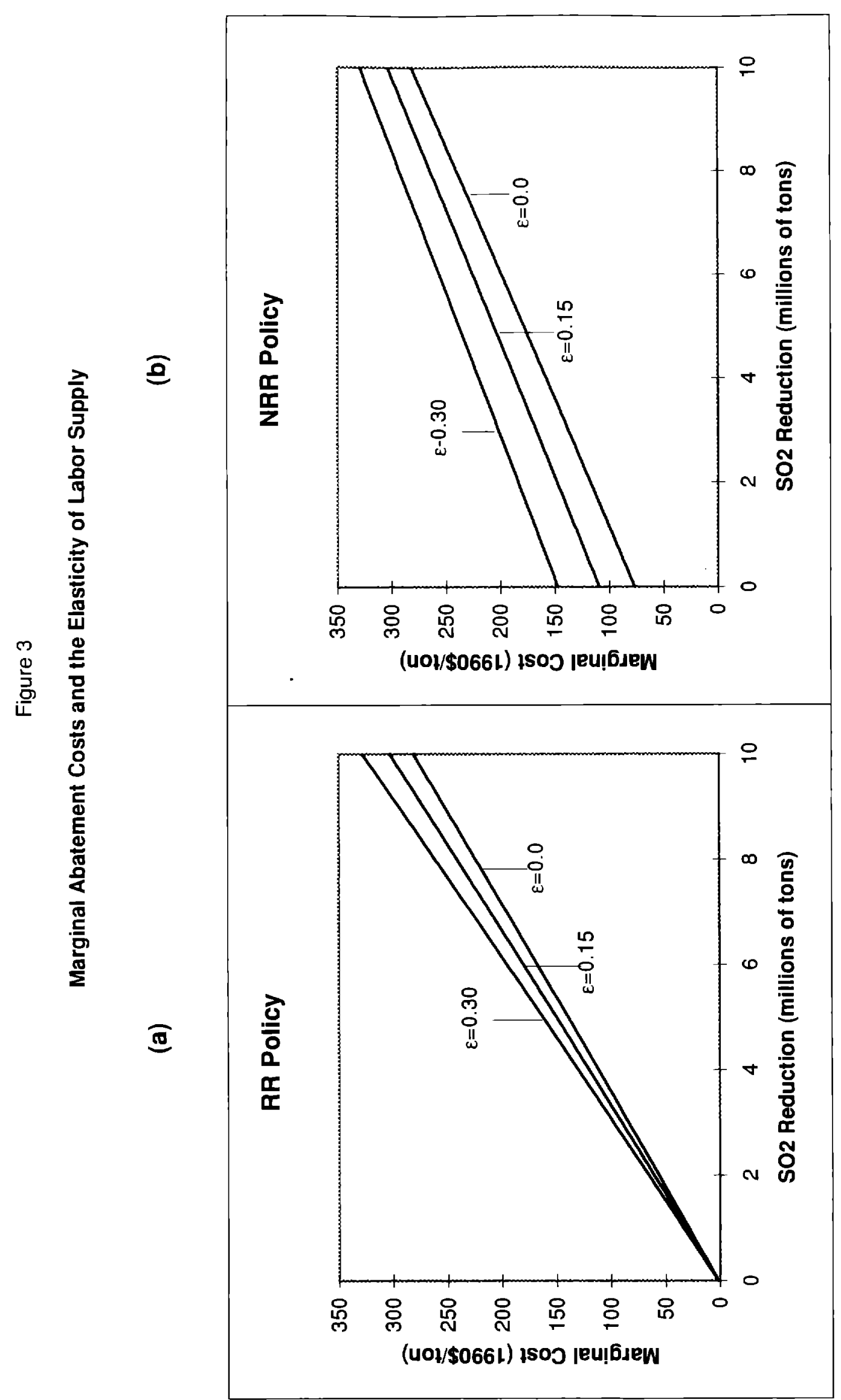




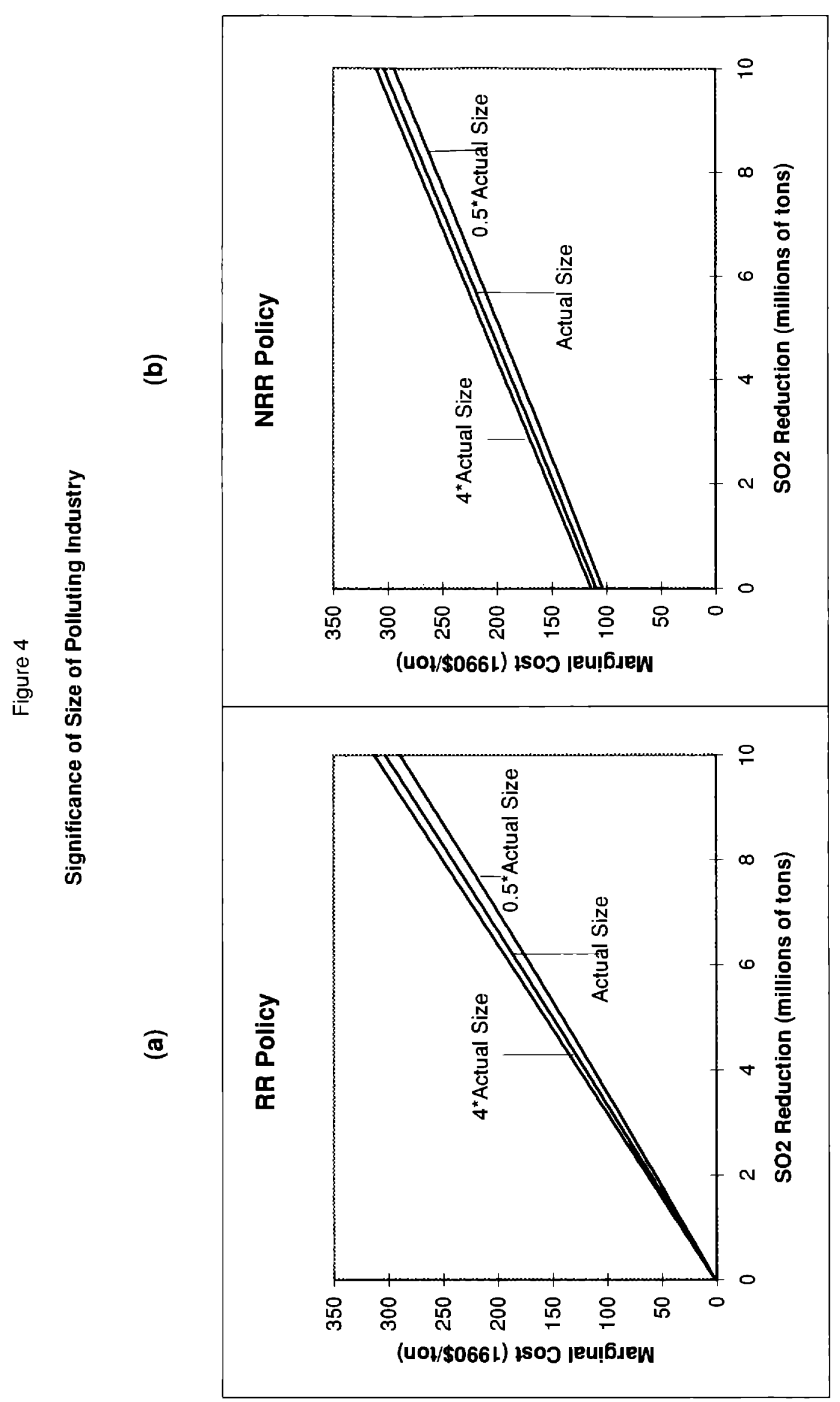




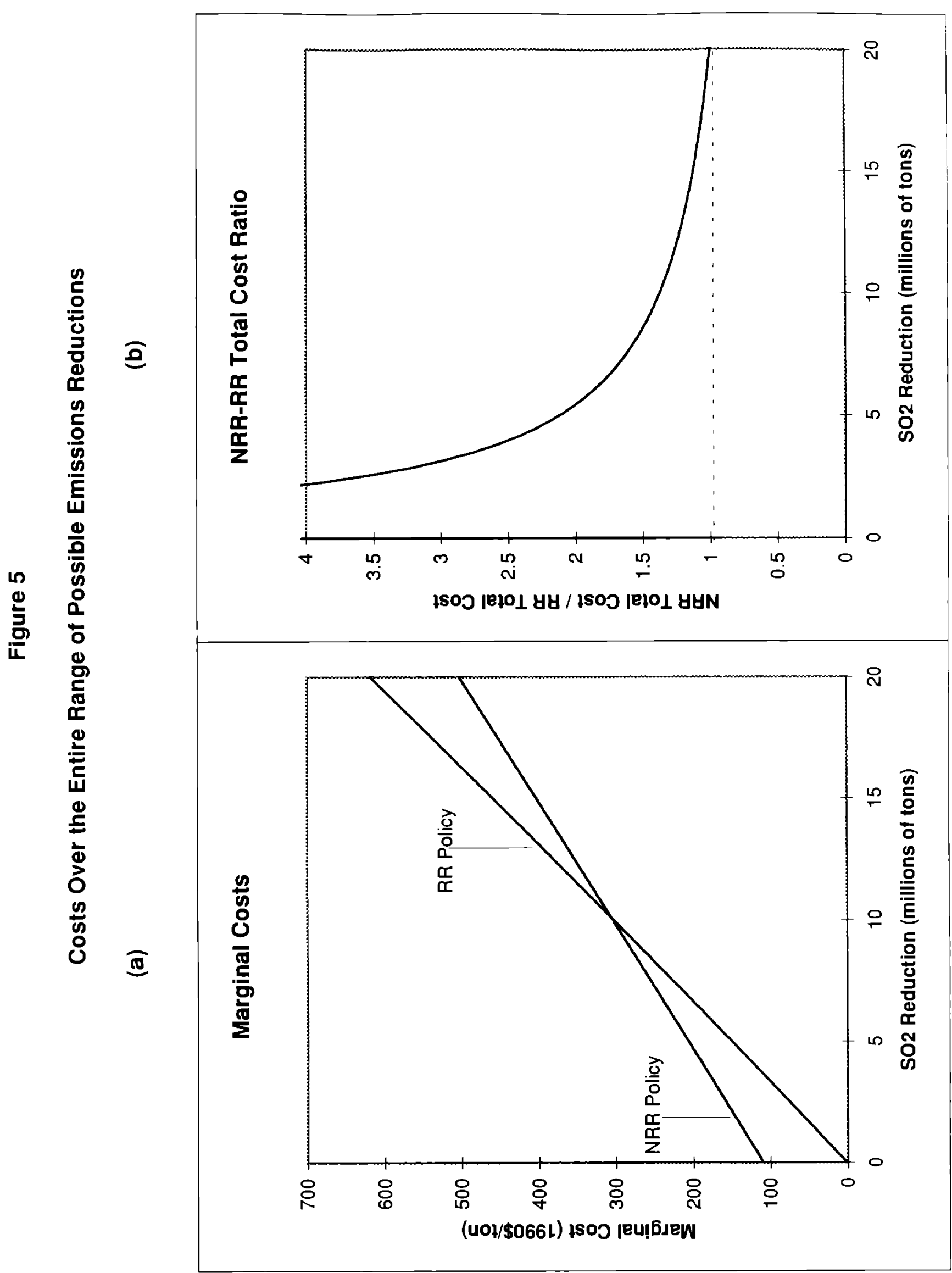


Table 1

\section{Benchmark Data and Parameters for the Numerical Model}

\section{A. Input-Output Flows}

( $S$ in millions of tons per year; all other flows in millions of 1990 dollars per year)

$\begin{array}{lllllll} & \mathrm{E} & \mathrm{G} & \mathrm{C}_{\text {| }} & \mathrm{C}_{\mathrm{N}} & \begin{array}{l}\text { Leisure } \\ \text { Time' }\end{array} & \begin{array}{l}\text { Total Input } \\ \text { Value }\end{array} \\ \mathrm{E} & 54.9 & 117151.1 & 63684.3 & 59.5 & 0.0 & 180949.8 \\ \mathrm{G} & 82557.5 & 6282925.6 & 199232.3 & 4047791.0 & 0.0 & 10612506.4 \\ \mathrm{~L} & 95337.4 & 4212429.7 & 0.0 & 0.0 & 6030873.9 & 10338641.0 \\ \begin{array}{l}\text { Total } \\ \text { Expenditure }\end{array} & 177949.8 & 10612506.4 & 262916.6 & 4047850.5 & & \\ \text { Rents } & 3000.0 & 0.0 & 0.0 & 0.0 & \\ \begin{array}{l}\text { Total Output } \\ \text { Value }\end{array} & 180949.8 & 10612506.4 & 262916.6 & 4047850.5 & & \\ \text { S (tons } \times 10^{6} \text { ) } & 10.0 & 0.0 & 0.0 & 0.0 & & \end{array}$

\section{B. Parameter Values}

$$
\begin{aligned}
& \sigma_{G}=\sigma_{E}=0.8 \\
& \sigma_{C I}=\sigma_{C N}=0.9 \\
& \sigma_{C}=0.85 ; \sigma_{U}=0.79^{2}
\end{aligned}
$$

\section{Sources}

Input-output flows for 1990 are from U.S. Department of Commerce, Bureau of Economic Analysis, Survey of Current Business, "Use of Commodities by Industries," April 1994. (These flows were then projected forward to the year 2000 using the growth rate of real GDP over the period 1984-1994, as reported in Table 699 of the 1995 Statistical Abstract of the United States.) Flows related to electric utilities were split into coal-fired and non-coal-fired utilities based on data from Table 7.1 of the Department of Energy, Energy Information Administration, Monthly Energy Review, September 1990. The input composition of the two consumer goods $C_{l}$ and $C_{N}$ is based on Table B of the May 1984 Survey of Current Business. Sulfur emissions data derive from Table 369 of the 1993 Statistical Abstract of the United States.

\footnotetext{
${ }^{1}$ Benchmark leisure time in 2000 is assumed to be 1.4 times observed work time.

${ }^{2} \sigma_{\cup}$ is calibrated to generate an uncompensated wage elasticity of labor supply of 0.15 .
} 
Table 2

Welfare Effects under Alternative Policles

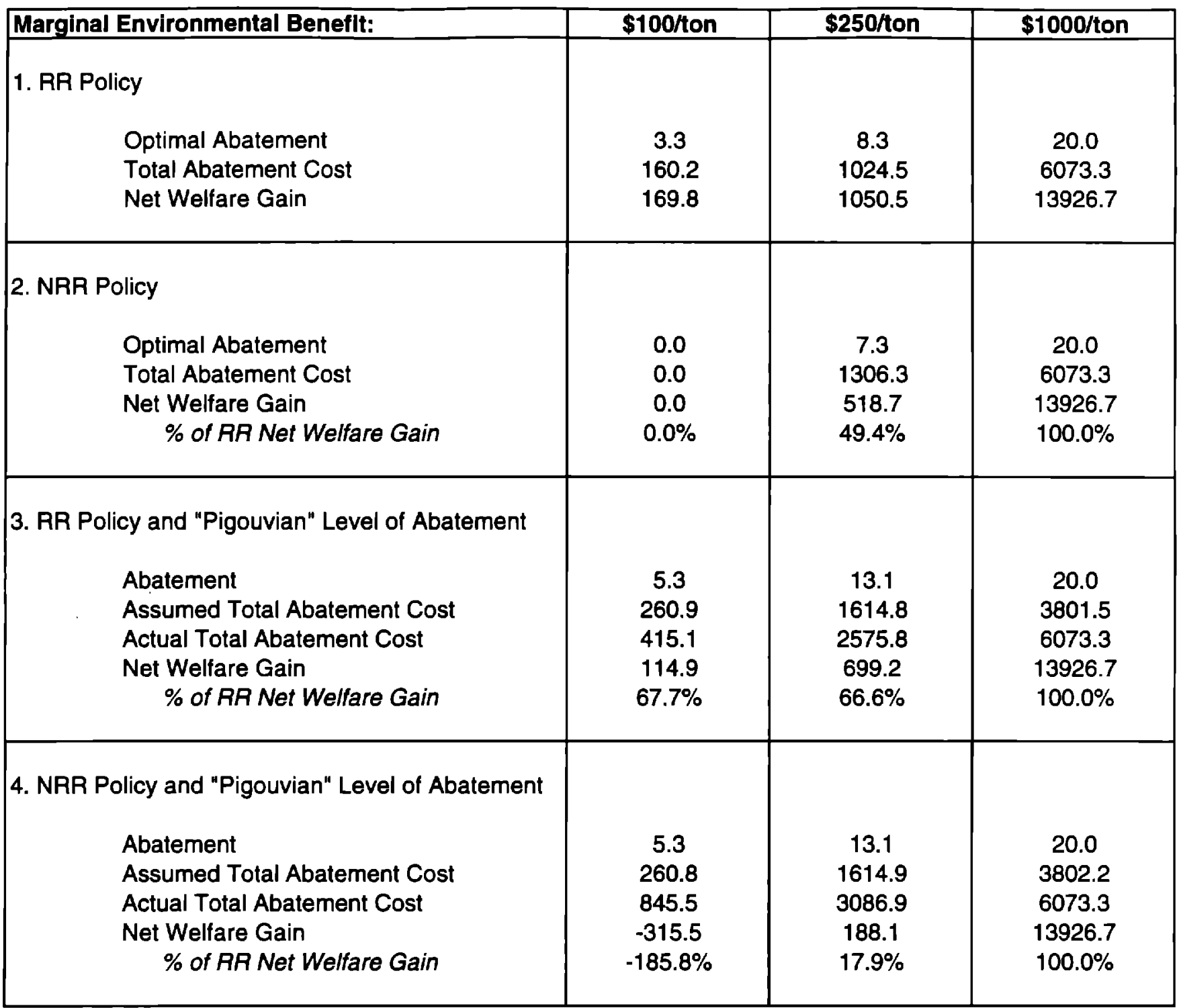

NOTE: Abatement figures are in millions of tons of SO2. Costs and welfare changes are in millions of 1990 dollars. 


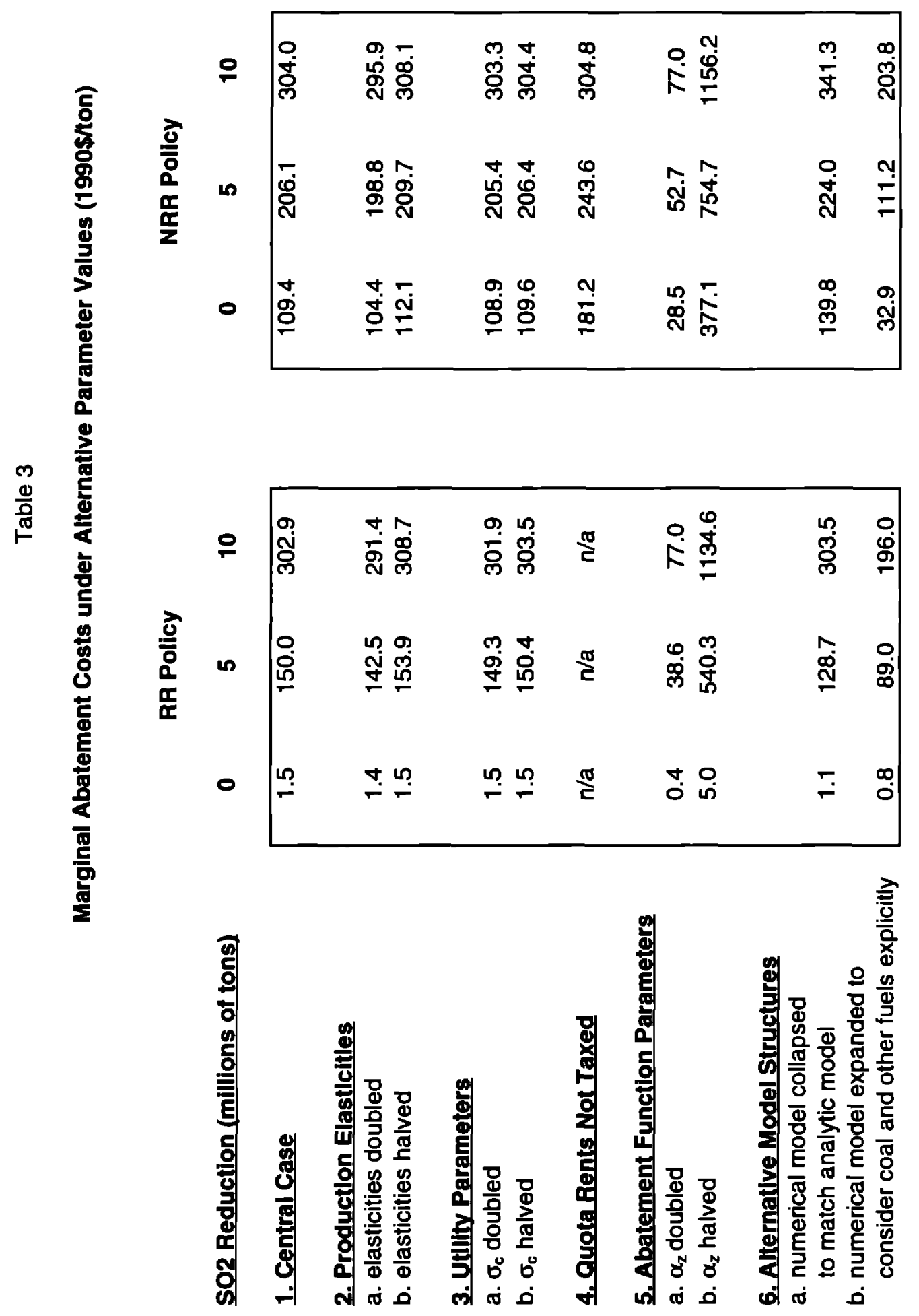

